Article

\title{
Shape Dependence of Falling Snow Crystals' Microphysical Properties Using an Updated Shape Classification
}

\author{
Sandra Vázquez-Martín ${ }^{1, *(\mathbb{C})}$, Thomas Kuhn ${ }^{1}\left(\mathbb{D}\right.$ and Salomon Eliasson ${ }^{2}(\mathbb{D}$ \\ 1 Division of Space Technology, Department of Computer Science, Electrical and Space Engineering, \\ Luleå University of Technology (LTU), 98128 Kiruna, Sweden; thomas.kuhn@ltu.se \\ 2 Swedish Meteorological and Hydrological Institute (SMHI), 60176 Norrköping, Sweden; \\ salomon.eliasson@smhi.se \\ * Correspondence: sandra.vazquez.martin@ltu.se
}

Received: 29 November 2019; Accepted: 4 February 2020; Published: 9 February 2020

\begin{abstract}
We present ground-based in situ snow measurements in Kiruna, Sweden, using the ground-based in situ instrument Dual Ice Crystal Imager (D-ICI). D-ICI records dual high-resolution images from above and from the side of falling natural snow crystals and other hydrometeors with particle sizes ranging from $50 \mu \mathrm{m}$ to $4 \mathrm{~mm}$. The images are from multiple snowfall seasons during the winters of 2014/2015 to 2018/2019, which span from the beginning of November to the middle of May. From our images, the microphysical properties of individual particles, such as particle size, cross-sectional area, area ratio, aspect ratio, and shape, can be determined. We present an updated classification scheme, which comprises a total of 135 unique shapes, including 34 new snow crystal shapes. This is useful for other studies that are using previous shape classification schemes, in particular the widely used Magono-Lee classification. To facilitate the study of the shape dependence of the microphysical properties, we further sort these individual particle shapes into 15 different shape groups. Relationships between the microphysical properties are determined for each of these shape groups.
\end{abstract}

Keywords: natural snow crystals; hydrometeors; classification; shape; microphysical properties

\section{Introduction}

The shape of ice particles is an important characteristic that affects the radiative impact of clouds. Accurate knowledge of the microphysical properties of clouds, including particle shape, is important in order to assure accurate cloud parameterizations in climate and meteorological forecast models, e.g., that presented in References [1,2]. Realistic cloud microphysical parameterizations are also essential for most cloud retrievals from satellite measurements. For instance, in order to retrieve quantities such as cloud water path or cloud effective radius, the underlying assumptions of particle shape, size, and distribution have a massive impact on the retrieval itself [3,4]. The unavoidable sensitivity of satellite retrievals to assumptions on ice particle properties, such as particle size, area, and the shape of snow crystals, is one of the dominating sources of uncertainties in cloud retrievals [5]. Although satellite observations of clouds are important validation sources for models, the role of clouds still poses one of the most substantial uncertainties in modeling the climate [6].

The shape of the snow crystals, which this paper primarily concerns, is formed by deposition, riming, aggregation, or a combination of these mechanisms [7]. Deposition refers to the process of water vapor freezing (depositing) onto ice nuclei or an existing ice crystal. If the ice crystals are in an environment with supercooled water droplets, these droplets may collide with and freeze onto the 
crystals, forming an icy surface layer and riming the crystal. As the snow crystals grow, they are more likely to collide with one another and to join together in a process called aggregation. The snowflake typically encounters several different temperature and humidity environments as they grow, resulting in a great variety of shapes, such as needles, stellar, plates, and graupel [8-17].

Nakaya and Sekido [8] developed a snow crystal morphology diagram ("Nakaya Diagram") tying the growth conditions of snow crystals to water vapor supersaturation (relative to ice) and temperature. This diagram has been adapted and translated into English by Libbrecht [16].

In 1951, the International Commission of Snow and Ice (ICSI) and the International Association of Cryospheric Sciences (IACS) characterized snow crystals into ten main shapes: plates, stellar crystals, columns, needles, spatial dendrites, capped columns, irregular particles, graupel, ice pellets, and hail. This classification, called the "Abstract of the International Classification for Snow" [18], is still used to distinguish different types of snow, including snow on the ground [19].

However, for some purposes, a more detailed classification is desirable. Magono-Lee [20] published a categorization scheme, still widely used, that catalogs snow and crystals into 80 categories. This classification scheme will, from now on, be referred to as the Magono-Lee classification. It divides shapes into categories and subcategories, allowing a logical shape labeling. For example, the shape "C1f" is a hollow, simple, columnar crystal, where $\mathrm{C}$ is columnar crystal, 1 is simple, and $\mathrm{f}$ is hollow.

More recently, Kikuchi et al. [21] presented an extensive revision of the Magono-Lee classification which catalogs snow crystals and other solid precipitation particles into 121 categories. This revised classification uses levels and sublevels in a similar way to Magono-Lee. However, Kikuchi et al. [21] merged the two main levels $N$ (needles) and C (columns), and consequently, some shapes that already existed in Magono-Lee received new labels.

There are also situations where a less detailed classification with only a few shapes is more desirable to use. For instance, the Abstract of the International Classification for Snow by ICSI and IACS provides a less detailed classification. However, instead of using two completely different classification schemes depending on how much detail one needs, it may be more practical to use one scheme, which allows for more or less detail. The Magono-Lee classification is such a scheme since it has different levels, and the main level with its eight categories could constitute one such coarse classification with less detail. Using Magono-Lee enables comparison with many previous studies that have used this classification. Additionally, using a less detailed classification defined by a few shape groups, which are based on the detailed Magono-Lee scheme, results in a classification method that is both flexible and compatible with previous classifications. On the one hand, updating the highly detailed underlying classification of Magono-Lee by only adding new shapes would guarantee compatibility with previous studies. On the other hand, grouping the shapes into shape groups would make it possible to accommodate the needs of studies that do not require or desire such a high level of detail. Regrouping for specific studies is very easy since the underlying shapes use the same classification, and the eight main-level categories of Magono-Lee would only define one of many possible ways of grouping.

Therefore, this study aims to first update the previous snow shape classification scheme of Magono-Lee by adding newly found shapes, then to sort particles into different shape groups, and finally to study the average microphysical properties of these shape groups. Hence, the study effectively aims to analyze the shape dependence of the snow particles' microphysical properties. For this, we present a dataset of falling snow particles that have been collected in Kiruna in northern Sweden with the new ground-based instrument Dual Ice Crystal Imager (D-ICI) [22] in Section 2. Section 3 describes how to classify these particles into shapes by updating the Magono-Lee classification scheme with shapes found by Kikuchi et al. [21] and Libbrecht [23] as well as shapes found in Kiruna as part of this study. The shape groups are defined in Section 4. Section 5 investigates the shape dependence of microphysical properties by using these shape groups. Finally, this study is summarized and concluded in Section 6. 


\section{Site and Measurements}

\subsection{Measurement Site}

Our measurements have been carried out in Kiruna, Sweden $\left(67.8^{\circ} \mathrm{N}, 20.4^{\circ} \mathrm{E}\right)$ using the D-ICI, the ground-based in situ instrument described in Kuhn and Vázquez-Martín [22]. Most of the measurements took place on the roof of the main building of the Swedish Institute of Space Physics (IRF) on the space campus at the height of about $15 \mathrm{~m}$ above the ground at an altitude of $425 \mathrm{~m}$ above mean sea level. The remaining measurements were done from the roof of the IRF Lidar laboratory located $950 \mathrm{~m}$ away from the space campus at the height of $5 \mathrm{~m}$ above ground. We consider these two locations close to each other and thus can further regard them as the same Kiruna measurement site.

Our dataset is from multiple snowfall seasons during the winters of 2014/2015 to 2018/2019. At the Kiruna site, each season lasts from about the beginning of November to the middle of May. Surface temperatures in Kiruna can reach down to $-43.3^{\circ} \mathrm{C}$ [24], and our data include temperatures down to $-27^{\circ} \mathrm{C}$. The IRF weather database [25], based on instruments $1.7 \mathrm{~km}$ away from the space campus and $2.44 \mathrm{~km}$ from our current measurement location, provides temperature and relative humidity used in this study.

\subsection{Instrument}

The D-ICI recorded images of falling snow crystals and other hydrometeors. After falling through the inlet, in-focus particles are detected and then imaged twice, simultaneously from above and from the side. These dual images are taken using two high-resolution imaging systems (resolution of about $10 \mu \mathrm{m}$ with a pixel resolution of $3.7 \mu \mathrm{m} / \mathrm{px}$; for a detailed description, see [22]). The additional information provided by a second image improves the shape classification.

An inlet camera is mounted to monitor the D-ICI inlet, such that it is viewing the inlet without obstructing the path of the falling particles. The camera is used to detect inlet blockage in order to exclude, in post-processing, any data affected by this.

\subsection{Image Processing}

Top-view images are used to determine particle size, cross-sectional area, area ratio, and aspect ratio by the automated process presented in detail in Kuhn and Vázquez-Martín [22]. The first steps are to remove the background features from uneven illumination and to remove out-of-focus particles. The particles then have their boundaries traced. These particle boundaries are further used to determine the properties of the particle.

The maximum dimension, $D_{\max }$, is used to describe particle size. Here, it is determined by the smallest diameter that completely encircles the particle on the image. The cross-sectional area, $A$, is the area enclosed by the particle boundary on the image, determined from the number of enclosed pixels. Equation (1) defines the area ratio, $A_{\mathrm{r}}$, as follows:

$$
A_{\mathrm{r}}=\frac{A}{\frac{\pi}{4} \cdot D_{\max }^{2}} .
$$

Equation (2) defines the aspect ratio, $A_{\mathrm{s}}$, as follows:

$$
A_{\mathrm{s}}=\frac{X}{Y}
$$

where $X$ is the width perpendicular to $Y$, the longest distance between any two points of the particle boundary. 


\section{Particle Shape Classification}

\subsection{Classification Method}

The particle shape classification is carried out manually by looking at both top- and side-view images simultaneously since these provide complementary information about the shape. The images provide enough detail so that they can be classified according to the Magono-Lee scheme.

Figure 1 shows a few examples of successfully classified snow particles. In some cases, classification is relatively simple with one image only, for example, the top view of the stellar crystal of example (a). However, looking at the side view of the same example, the ice particle's shape may be mistaken for a needle type, as it looks similar to example case (b), which is of needle shape. Thus, determining the shape from one image is challenging even when using high-resolution images due to ambiguities arising in the case of unfavorable orientation in that image.

Cases (c) and (d) are more examples, which, in the side view, appear to have a similar shape. However, from the top-view images, we can distinguish two different shapes: (c) has a dendritic crystal or stellar shape, and (d) is a bullet capped with a dendrite. Similarly, particles in (e) and (f) appear to have similar shapes in the side view, i.e., hexagonal plate shape, however, from the top-view images, we can distinguish two different shapes: (e) is a capped column, and (f) is a hexagonal plate capped on one side with a thin plate. In a few cases, it is difficult to specify the shape despite the availability of top- and side-view images. For instance, we cannot distinguish if (g), (h), or (i) are the same shape, i.e., if they are graupel-like snow or densely rimed ice crystals. For such cases, we determine that they have a graupel shape.

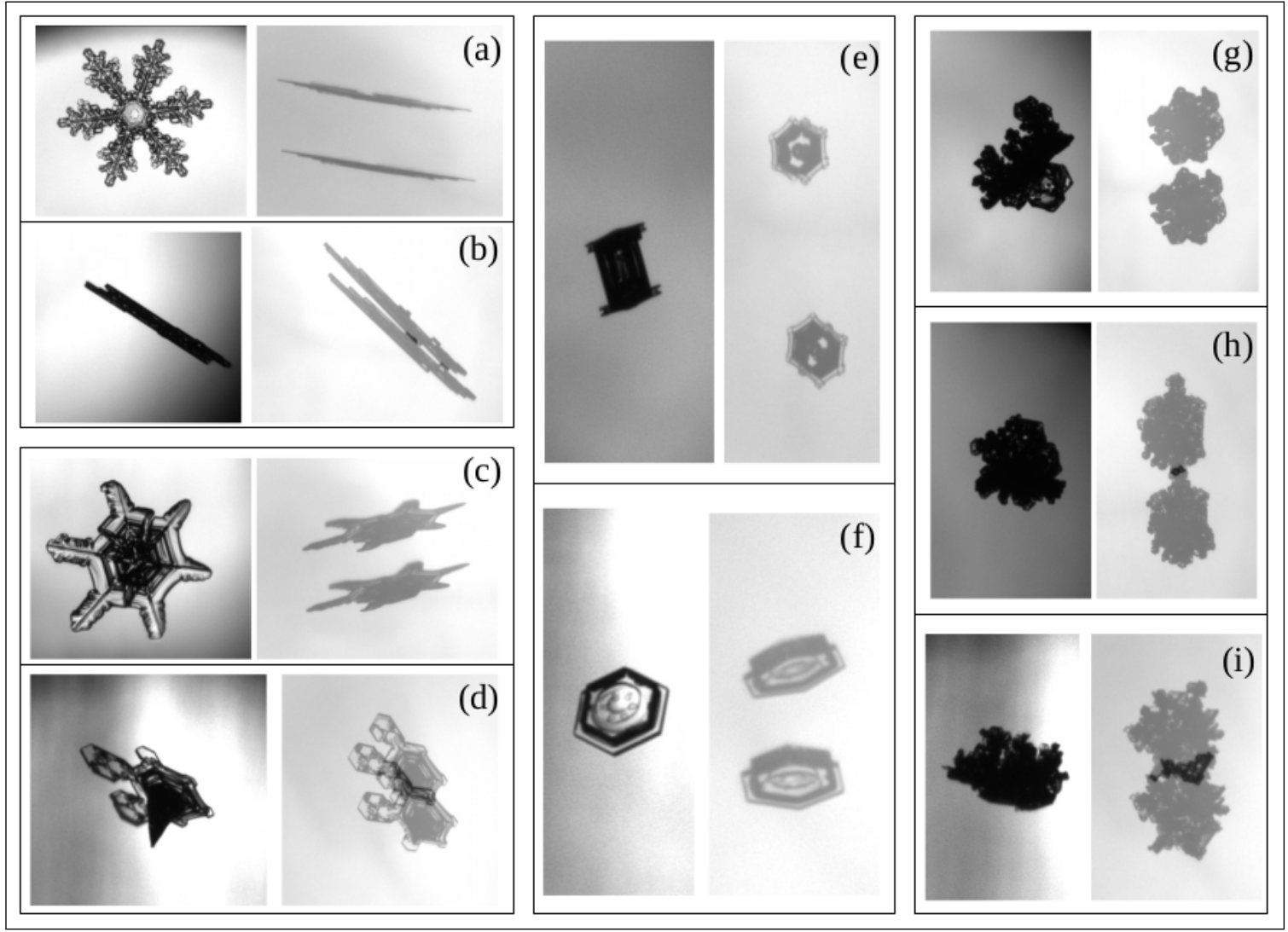

Figure 1. Shape classification is less ambiguous with dual images. Panels (a-i) show nine examples of different particles with side views (right) and top views (left). Discussion of these examples is in the text. 


\subsection{Recent Updates}

When classifying snow particles using the shape classes from the Magono-Lee classification, for some particles, a suitable shape class is missing. To these particles, we have either assigned a shape found in more recent literature or a new shape class. In both cases, we have chosen shape labels that are consistent with the Magono-Lee nomenclature. Thus, this new classification is an update of the Magono-Lee classification, which is only an extension of this original classification scheme, so that the many previous studies or datasets that have been using Magono-Lee may still be used as a reference.

Some new shapes appear in the study of Kikuchi et al. [21], which uses labels that are different from Magono-Lee. Therefore, we include these shapes with new labels consistent with Magono-Lee.

Other shapes are added but keep the same labels as in Kikuchi et al. [21], as they are not conflicting with Magono-Lee.

We also add some shapes observed by Libbrecht [23] as an extension of the Magono-Lee classification. Since shapes by Libbrecht [23] do not have any labels, only a shape name, they are added by assigning compatible labels that are consistent with the Magono-Lee nomenclature.

Table 1 shows the shapes added from Libbrecht [23] and Kikuchi et al. [21].

Table 1. Added shapes from Libbrecht [23] and Kikuchi et al. [21].

\begin{tabular}{lc}
\hline Particle Shape Name (Old Label) & New Label \\
\hline Kikuchi et al. [21]: & \\
Combination of bullets with plates (CP2c) & $\mathrm{CP} 2 \mathrm{f}$ \\
Combination of bullet with dendrites (CP2d) & $\mathrm{CP} 2 \mathrm{~g}$ \\
Seagull-type crystals (CP9a-CP9e) & $\mathrm{CP} 4 \mathrm{a}$ \\
Bullet with plate & $\mathrm{CP} 2 \mathrm{a}$ \\
Plate with needles & $\mathrm{CP} 3 \mathrm{~d}$ \\
Plate with columns & $\mathrm{CP} 3 \mathrm{e}$ \\
Aggregation of combinations of columns and bullets & $\mathrm{A} 1 \mathrm{a}$ \\
Aggregation of combinations of plates and dendrites & $\mathrm{A} 2 \mathrm{a}$ \\
Aggregation of combinations of columns, planes and & $\mathrm{A} 3 \mathrm{a}$ \\
crossed plates & \\
Frozen cloud particle & $\mathrm{H} 1 \mathrm{a}$ \\
Chained frozen cloud particles & $\mathrm{H} 1 \mathrm{~b}$ \\
Frozen small raindrop & $\mathrm{H} 1 \mathrm{c}$ \\
Sleet particle & $\mathrm{H} 2 \mathrm{a}$ \\
Ice pellet & $\mathrm{H} 3 \mathrm{a}$ \\
\hline Libbrecht [23]: & \\
Twin columns & $\mathrm{C} 1 \mathrm{j}$ \\
Triangular form/plate & $\mathrm{P} 1 \mathrm{~g}$ \\
Hollow plate & $\mathrm{P} 1 \mathrm{i}$ \\
Split plate & $\mathrm{P} 1 \mathrm{k}$ \\
Split stellar crystal & $\mathrm{P} 11$ \\
Double plate & $\mathrm{P} 1 \mathrm{o}$ \\
Arrowhead twins & $\mathrm{S} 4$ \\
Crossed plates & $\mathrm{S} 5$ \\
\hline
\end{tabular}




\subsection{New Shapes from Kiruna}

New shapes only found in Kiruna and not yet described are also included as an extension of the Magono-Lee classification with labels compatible with Magono-Lee. These 34 new shapes are named as shown in Table 2.

Table 2. The 34 new shapes found in Kiruna: Figure 2 shows example images of all these new shapes.

\begin{tabular}{lc}
\hline Particle Shape Name & New Label \\
\hline Rectangular plate & $\mathrm{P} 1 \mathrm{~h}$ \\
Plate with a central hole & $\mathrm{P} 1 \mathrm{j}$ \\
Irregular split plate & $\mathrm{P} 1 \mathrm{~m}$ \\
Irregular split stellar crystal & $\mathrm{P} 1 \mathrm{n}$ \\
Double stellar crystal & $\mathrm{P} 1 \mathrm{p}$ \\
Stellar over plate & $\mathrm{P} 1 \mathrm{q}$ \\
Triangular form with plates at ends & $\mathrm{P} 2 \mathrm{~h}$ \\
Triangular form with dendrites at ends & $\mathrm{P} 2 \mathrm{i}$ \\
Concentric plates with sector-like extensions & $\mathrm{P} 2 \mathrm{j}$ \\
Concentric plates with stellar or dendritic extensions & $\mathrm{P} 2 \mathrm{k}$ \\
Column with plate and dendrite & $\mathrm{CP} 1 \mathrm{~d}$ \\
Asymmetric capped column (with plates) & $\mathrm{CP} 1 \mathrm{e}$ \\
Multiple capped column with dendrites & $\mathrm{CP} 1 \mathrm{f}$ \\
Asymmetric column with dendrites & $\mathrm{CP} 1 \mathrm{~g}$ \\
Bullet with plate and dendrite & $\mathrm{CP} 2 \mathrm{c}$ \\
Bullet with two plates & $\mathrm{CP} 2 \mathrm{~d}$ \\
Bullet with two dendrites & $\mathrm{CP} 2 \mathrm{e}$ \\
Combination of bullets (capped bullets) & $\mathrm{CP} 2 \mathrm{f}$ \\
Asymmetric combination of bullets & $\mathrm{CP} 2 \mathrm{i}$ \\
Aggregation of multiple capped columns & A4a \\
Aggregation of needles and sheaths & A5a \\
Aggregation of stellar crystals & A6a \\
Aggregation of dendrite crystals & A7a \\
Aggregation of plates & A8a \\
Aggregation of bullets & A9a \\
Aggregation of bullet rosettes and capped bullets & A9b \\
Aggregation of branches & A10a \\
Aggregation of seagull & A11a \\
Aggregation of malformed crystals & A12a \\
Aggregation of irregular particles & A13a \\
Aggregation of frozen small raindrops and snow crystals & A14a \\
Rimed bundle & R1e \\
Rimed capped bullet & R1f \\
Raindrop & H4a \\
\hline & \\
\hline
\end{tabular}

Figure 2 shows example images of all the new shapes found in Kiruna. In some cases, more images of the same shape are shown in order to show the small differences that can be found within the same shape, i.e., the accepted variability within the shape classification. In other cases, side- and top-view images of the particle shape are shown for better shape description. For instance, in shape $C P 2 d$, only by looking at the side view of the first particle can we see the bullet with two plates. 


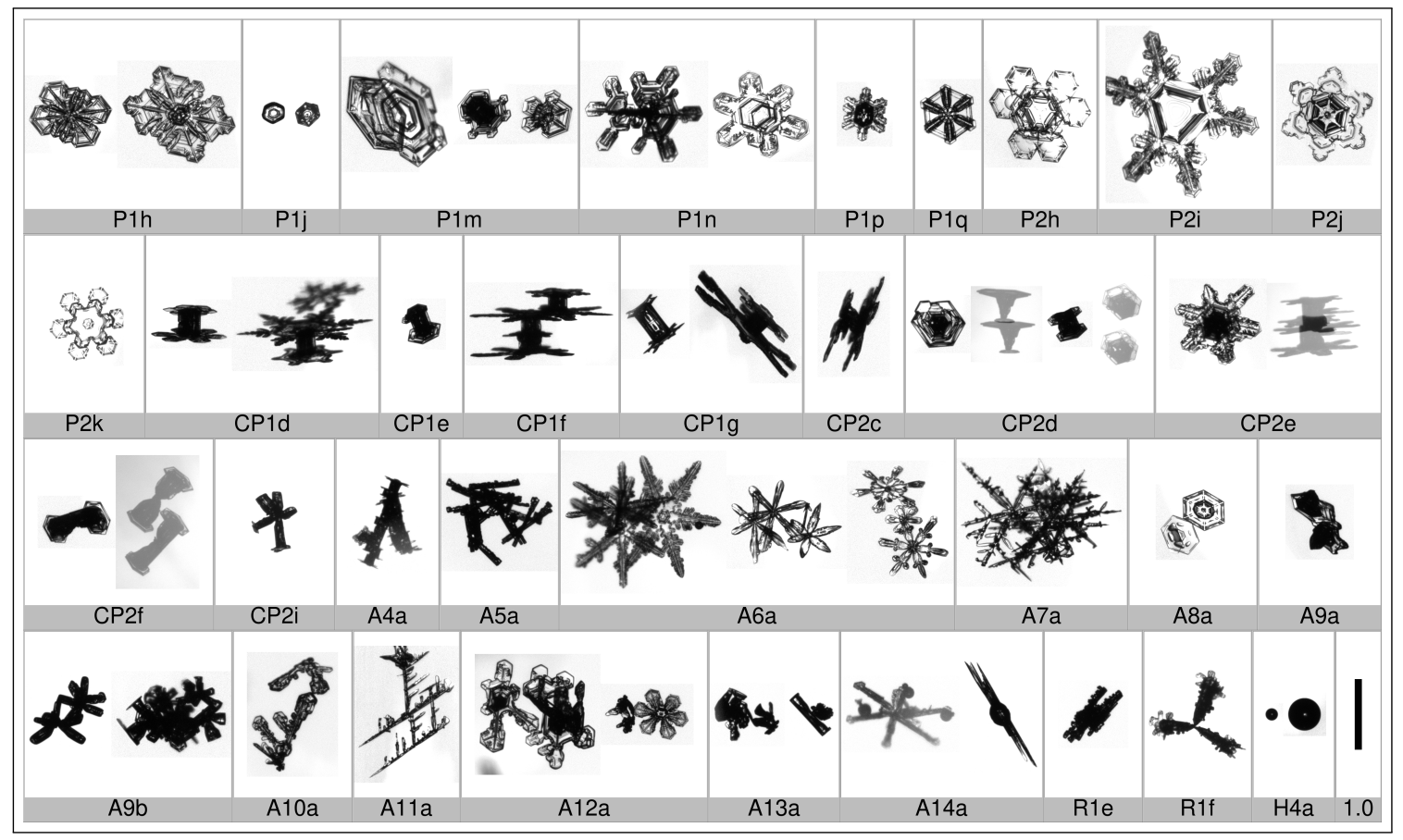

Figure 2. The 34 new shapes found in Kiruna: Table 2 shows their completed name. The same scaling is applied to all images; a 1.0-mm scale bar is shown as reference. In some cases, more images of the same shape are shown to indicate possible differences found in the same shape. In other cases, sideand top-view images of the particle shape are shown for better shape description.

The resulting updated classification of Magono-Lee has 135 shapes, including the 34 new shapes from Kiruna. In Appendix A, Table A1 shows the complete names of all these shapes. Figures A1 and A2 show images of all the particle shapes taken by D-ICI. The 34 new shapes found in Kiruna are highlighted by thick gray frames.

\section{Shape Groups}

The microphysical properties (particle size, cross-sectional area, and area ratio) are determined from the particle images taken with D-ICI. After classifying the particles, one can study these properties for specific shapes or how the properties depend on them. It is challenging to study the characteristics of all 135 shapes since most particle shapes infrequently appear so that statistically significant results are hard to achieve.

Furthermore, even if we had found enough examples of every single shape to achieve statistical significance, it may be hard for the models to utilize this level of detail. Additionally, due to natural variability, the encountered variation in microphysical properties of one shape would, in many cases, be larger than shape-to-shape variations.

Therefore, to analyze the shape properties, it seemed to be more useful to use a classification based on only a small number of shape groups, instead of the 135 individual shapes. In the following section, we describe how we gather the 135 shapes into 15 shape groups, which are then used to study shape dependencies. However, these shape groups can be assembled differently into, for instance, less than 15 groups, depending on the needs of the study. In this case, 15 shape groups were defined in an attempt to simplify shape description while still maintaining some level of detail.

In a similar approach to Magono-Lee [20], we gather the shapes into 15 groups with comparable morphological characteristics. Magono-Lee's main level P = Plane crystal contains both plate-like shapes and stellar shapes; however, we wish to separate the two for this study and, hence, group them somewhat differently. Therefore, the groups used here do not exactly follow the main levels of Magono-Lee. This is not seen as incompatible to the Magono-Lee classification scheme. Rather, 
the detailed classification using the updated Magono-Lee shapes from Section 3 allows one to group shapes according to the needs or interests, which may differ from study to study. In this sense, the grouping used here is not seen as rigid and definitive but as a first useful attempt to study snow particle characteristics depending on shape. These 15 shape groups are listed in Table 3.

Table 3. Shape groups (1-15).

\begin{tabular}{l}
\hline \multicolumn{1}{c}{ Shape Groups (1-15) } \\
\hline (1) Needles and thin or long columns \\
(2) Crossed needles and crossed columns \\
(3) Thick columns and bullets \\
(4) Capped columns and capped bullets \\
(5) Plates \\
(6) Stellar crystals \\
(7) Bullet rosettes \\
(8) Branches \\
(9) Side planes \\
(10) Spatial plates \\
(11) Spatial stellar crystals \\
(12) Graupel \\
(13) Ice and melting or sublimating particles \\
(14) Irregulars and aggregates \\
(15) Spherical particles
\end{tabular}

Thus, we sort particle shapes that look similar, such as particles with needle-like shapes and thin columns, into groups of shared morphology. Therefore, even rimed particles can be included in such a group, as long as they appear to have the same type of morphology. Graupel particles, which do not appear to have a particular shape, are grouped separately as Graupel. Tables 4-7 provide detailed descriptions of the 15 shape groups. For each group, particle images of all the shapes that define that group are shown. In Appendix B, Table A2 lists for each shape group all shapes with their labels and names. 
Table 4. Shape groups and their descriptions (part 1): For each of the 15 groups, images of all included shapes are shown. The complete names of these shapes are shown in Table A2 in Appendix B.

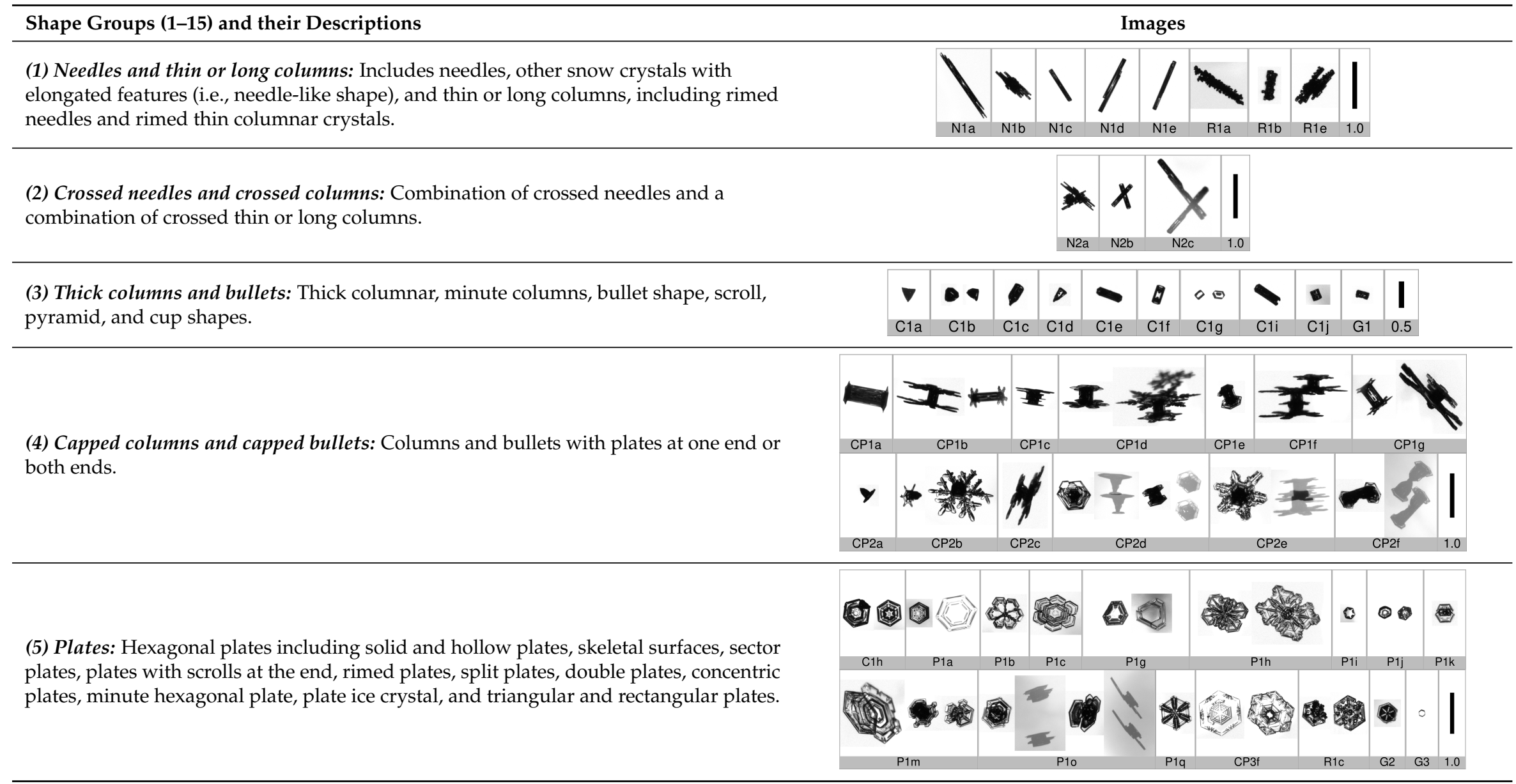


Table 5. Shape groups and their descriptions (part 2): For caption, see Table 4.

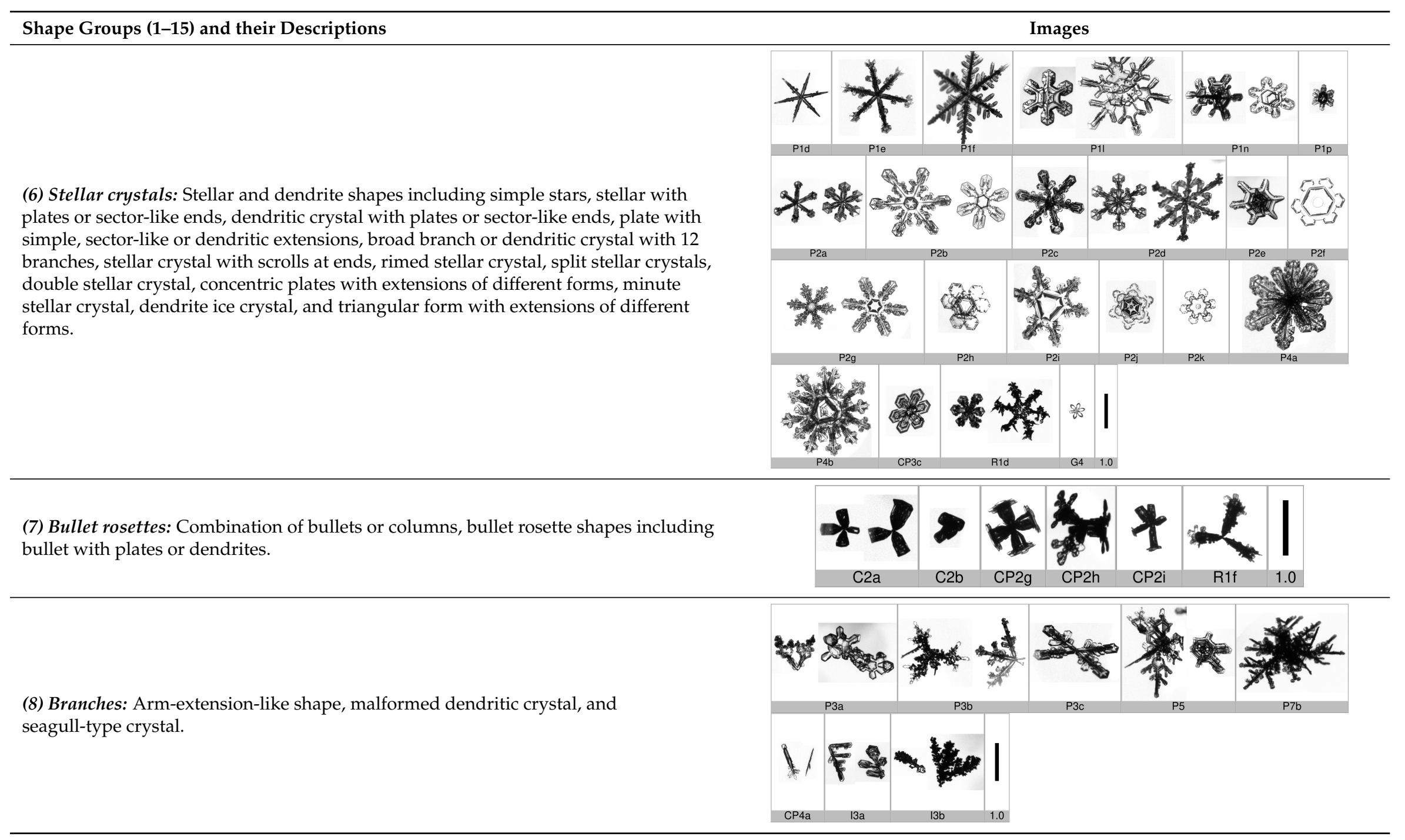


Table 6. Shape groups and their descriptions (part 3): For caption, see Table 4.

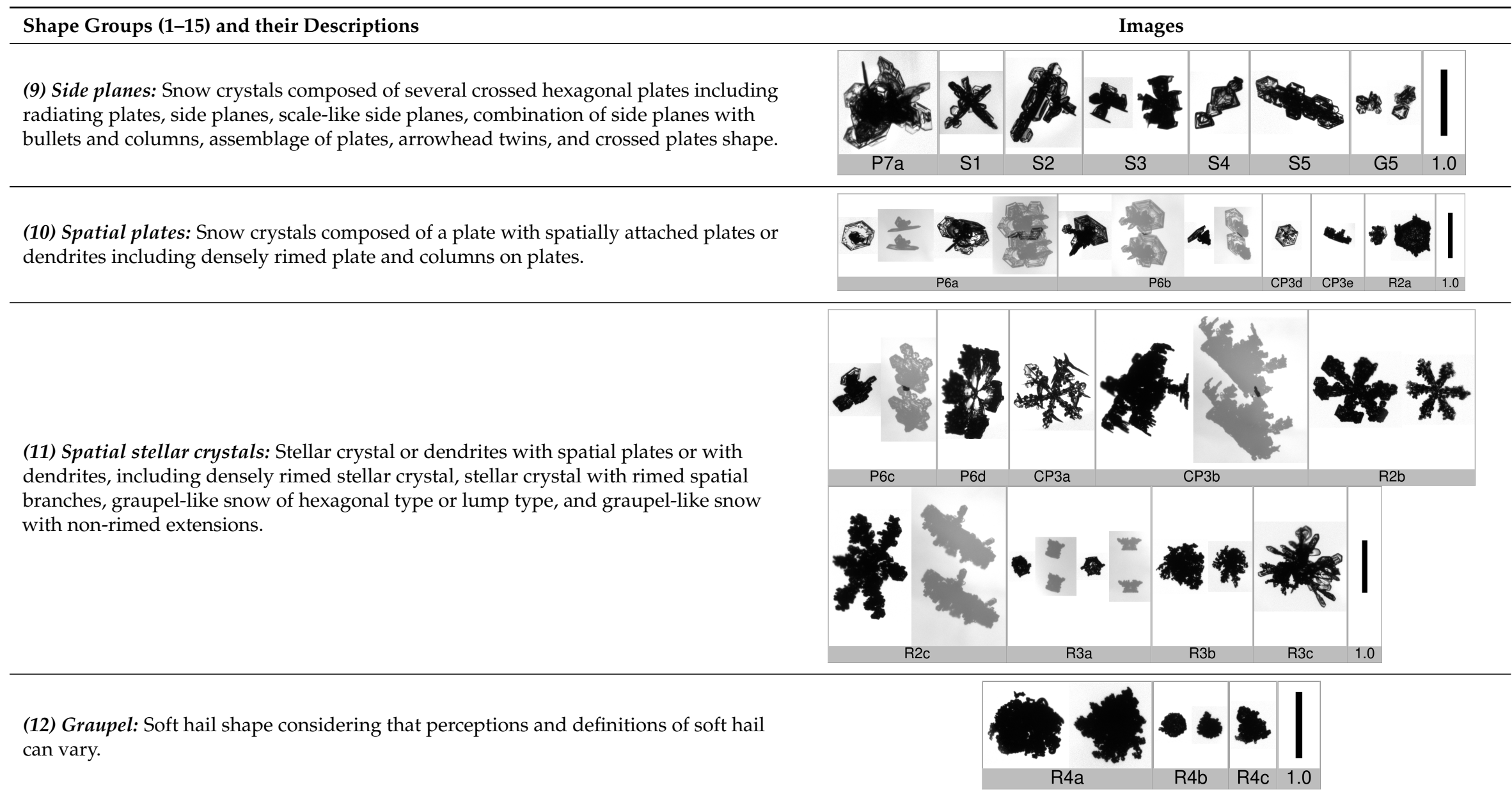


Table 7. Shape groups and their descriptions (part 4): For caption, see Table 4.

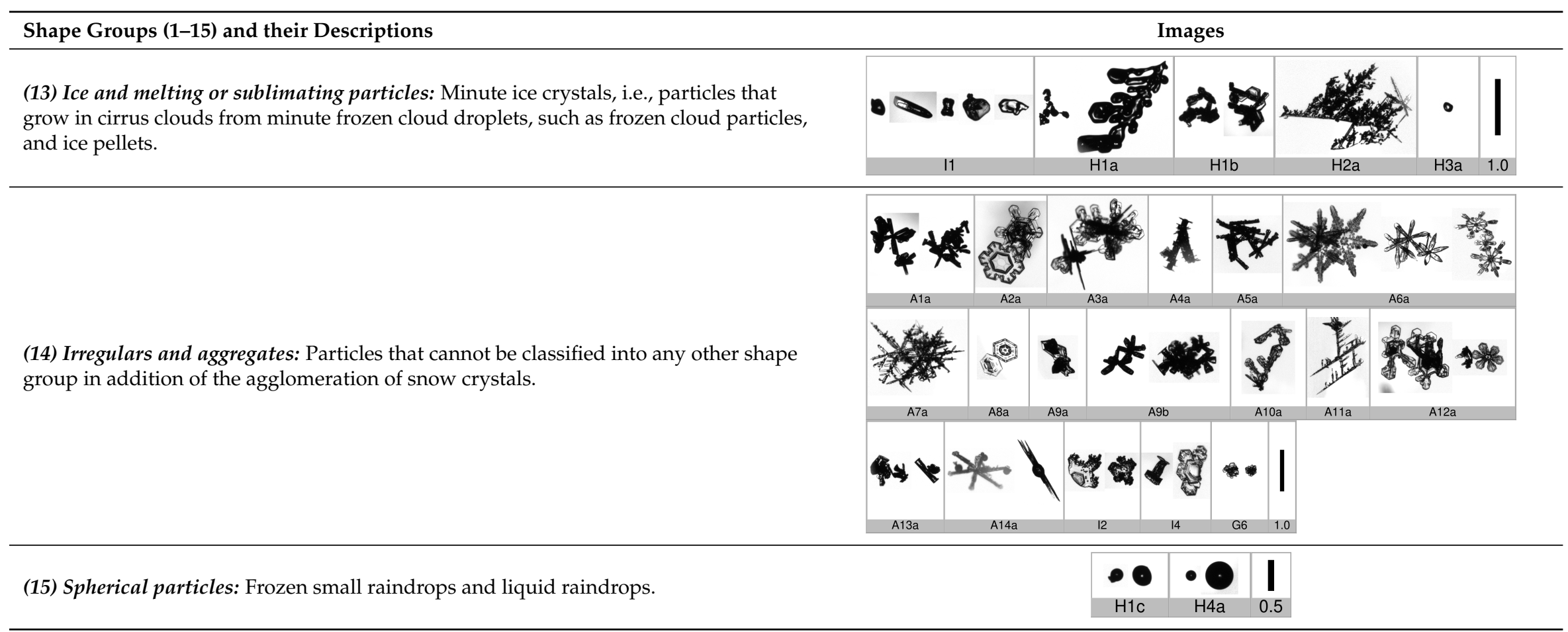




\section{Properties of Shape Groups}

In this section, we analyze the properties of the shape groups defined in Section 4. More than 10,000 images were taken during snowfall events from 2014 to 2019. As mentioned in Kuhn and Vázquez-Martín [22], we only consider particles that are completely in the field of view for analysis. In total, we found 3165 particles from 67 days that fulfilled these criteria and they make up the dataset further referred to in this study.

\subsection{Occurrence and Properties}

Figure 3 shows the frequency of occurrence of each shape group. We note that, in our dataset, shape group (8) Branches is the most common, occurring $20 \%$ of the time, followed by groups (14) Irregulars and aggregates, (9) Side planes, and (1) Needles and thin or long columns occurring $17 \%, 14 \%$, and $11 \%$ of the time, respectively. The other shape groups have frequencies below $7.5 \%$.

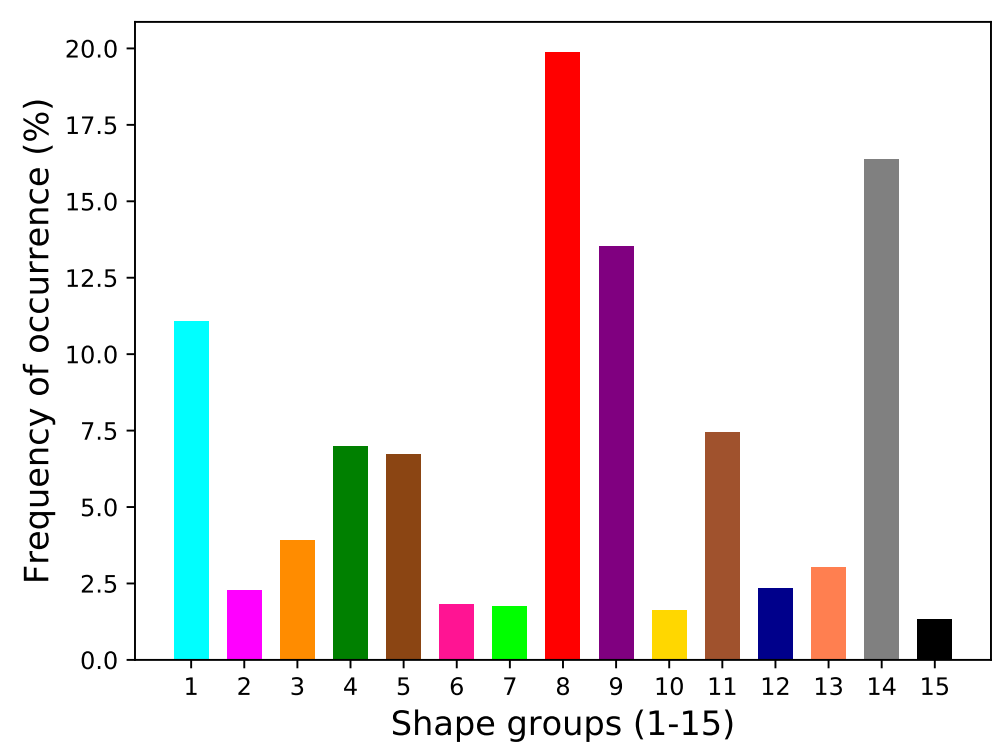

Figure 3. Occurrence of shape groups (1-15).

Figure $4 \mathrm{a}-\mathrm{c}$ shows the particle size, $D_{\max }$; cross-sectional area, $A$; and area ratio, $A_{\mathrm{r}}$, respectively, for each shape group. These quantities are shown by their median, represented as a point. The data spread is given by the percentiles $84.1 \%$ and $15.9 \%$, which together correspond to $\pm 1 \sigma$ (standard deviation) if the distribution was normal (or Gaussian). The same data are shown in Table 8.

In Figure 4a, we note that shape group (6) Stellar crystals has the largest particle size with median $D_{\max }=1450 \mu \mathrm{m}$, followed by shape groups (2) Crossed needles and crossed columns, (7) Bullet rosettes, (8) Branches, (9) Side planes, and (11) Spatial stellar crystals with $D_{\max }>1000 \mu \mathrm{m}$. Shape groups (3) Thick columns and bullets, (5) Plates, (13) Ice and melting or sublimating particles, and (15) Spherical particles have the smallest sizes with median $D_{\max }<500 \mu \mathrm{m}$. Shape groups (11) Spatial stellar crystals and (14) Irregulars and aggregates have the widest spread ranging over $1000 \mu \mathrm{m}$, whereas shape groups (13) Ice and melting or sublimating particles and (15) Spherical particles have the smallest data spread with less than $300 \mu \mathrm{m}$.

Figure $4 \mathrm{~b}$ illustrates that shape group (6) Stellar crystals with the largest particle size also has the largest cross-sectional area, with median $A=6.34 \times 10^{-7} \mathrm{~m}^{2}$, followed by shape groups (7) Bullet rosettes, (8) Branches, (9) Side planes, and (11) Spatial stellar crystals with median $A>3.0 \times 10^{-7} \mathrm{~m}^{2}$. In general, groups with large $D_{\max }$ also have large areas. However, there are exceptions, such as shape group (2) Crossed needles and crossed columns. While this shape group is among the groups with the largest $D_{\max }$, it is also among the shape groups with smaller areas. This is due to its shape leading to a 
minimal area ratio, as can be seen in Figure 4c. We note that shape groups (1) Needles and thin or long columns and (2) Crossed needles and crossed columns have the smallest area ratios with $A_{\mathrm{r}}<0.2$. Shape group (15) Spherical particles has an area ratio close to one, as expected.

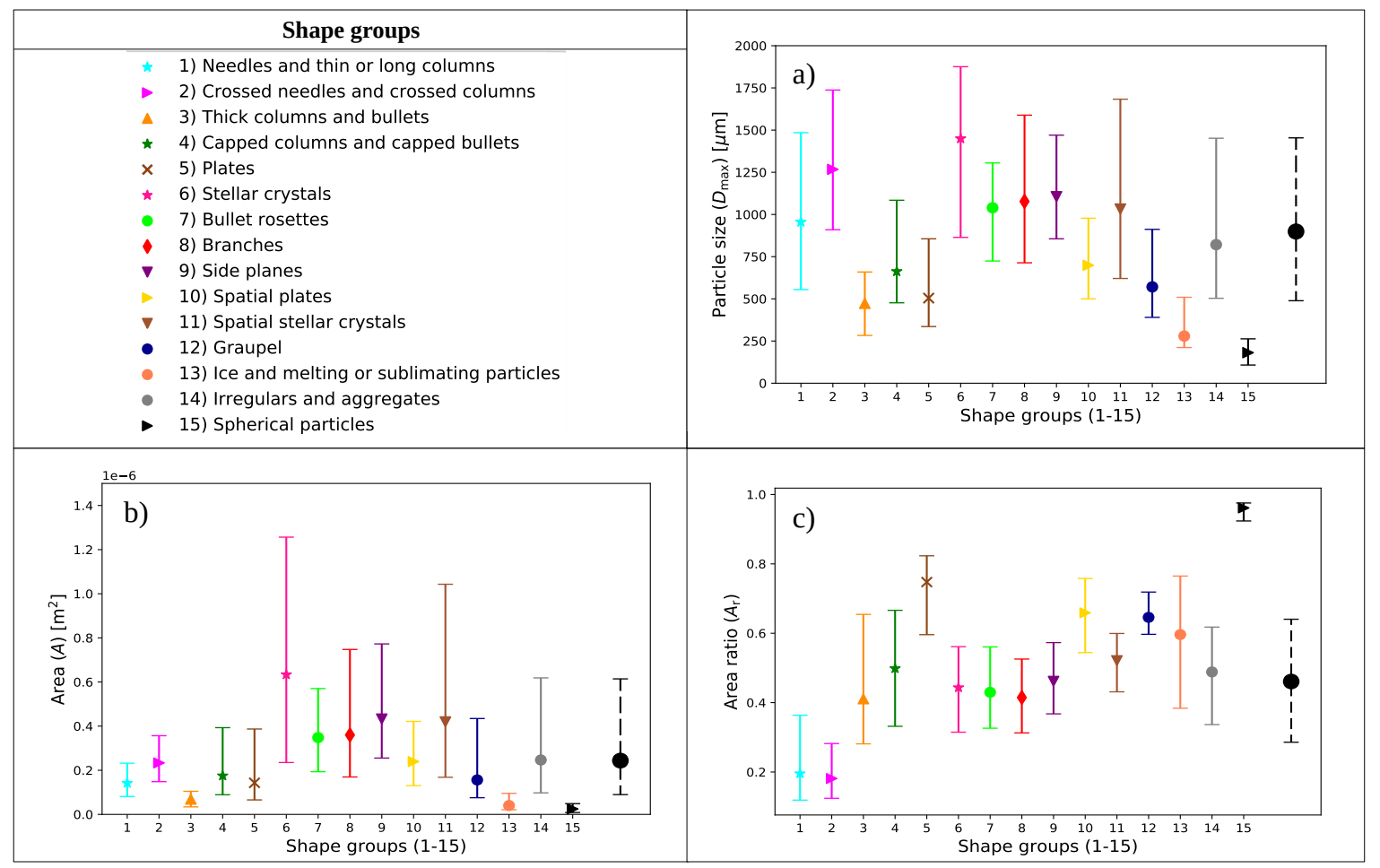

Figure 4. Microphysical properties of snow crystals for each shape group are shown in solid lines. The median and the spread corresponding to (a) particle size, $D_{\max }$; (b) cross-sectional area, $A$; and (c) area ratio, $A_{\mathrm{r}}$, are shown. Values of the median are represented as points. Lower and upper ends of the vertical bars are given by the percentiles $15.9 \%$ and $84.1 \%$, respectively, representing the data spread. For comparison, median and the spread corresponding to all data (regardless of shape) are also shown in black dashed lines.

Table 8. The total number of particles, \#; particle size, $D_{\max }$; cross-sectional area, $A$; and area ratio, $A_{\mathrm{r}}$, for the shape groups. The median and percentiles $15.9 \%$ and $84.1 \%$ are displayed. For comparison, results for all the data, i.e., all the shape groups together regardless of shape, are also shown.

\begin{tabular}{|c|c|c|c|c|c|c|c|c|c|c|}
\hline \multirow{2}{*}{ Shape Groups (1-15) } & \multirow{2}{*}{$\#$} & \multicolumn{3}{|c|}{$D_{\max } / \mu \mathrm{m}$} & \multicolumn{3}{|c|}{$A / 10^{-9} \mathrm{~m}^{2}$} & \multicolumn{3}{|c|}{$A_{\mathrm{r}}$} \\
\hline & & Median & $15.9 \%$ & $84.1 \%$ & Median & $15.9 \%$ & $84.1 \%$ & Median & $15.9 \%$ & $84.1 \%$ \\
\hline (1) Needles/long columns & 350 & 956 & 555 & 1485 & 142 & 81.3 & 232 & 0.195 & 0.119 & 0.363 \\
\hline (2) Crossed needles/col. & 72 & 1267 & 910 & 1737 & 233 & 148 & 357 & 0.181 & 0.124 & 0.282 \\
\hline (3) Thick columns & 124 & 473 & 283 & 659 & 69.0 & 34.1 & 105 & 0.411 & 0.281 & 0.654 \\
\hline (4) Capped columns/bull. & 221 & 662 & 476 & 1084 & 175 & 89.1 & 393 & 0.498 & 0.332 & 0.666 \\
\hline (5) Plates & 213 & 504 & 336 & 856 & 143 & 65.7 & 387 & 0.748 & 0.596 & 0.823 \\
\hline (6) Stellar crystals & 57 & 1450 & 864 & 1876 & 634 & 235 & 1260 & 0.443 & 0.315 & 0.561 \\
\hline (7) Bullet rosettes & 55 & 1040 & 724 & 1305 & 348 & 194 & 570 & 0.430 & 0.326 & 0.561 \\
\hline (8) Branches & 629 & 1078 & 714 & 1589 & 360 & 170 & 748 & 0.415 & 0.313 & 0.526 \\
\hline (9) Side planes & 428 & 1105 & 856 & 1470 & 432 & 255 & 773 & 0.462 & 0.368 & 0.573 \\
\hline (10) Spatial plates & 51 & 699 & 500 & 978 & 239 & 131 & 422 & 0.659 & 0.544 & 0.758 \\
\hline (11) Spatial stellar cryst. & 235 & 1032 & 621 & 1683 & 420 & 168 & 1040 & 0.521 & 0.431 & 0.599 \\
\hline (12) Graupel & 74 & 571 & 390 & 912 & 156 & 75.6 & 435 & 0.646 & 0.597 & 0.719 \\
\hline (13) Ice/melting particles & 96 & 279 & 212 & 509 & 40.2 & 21.2 & 95.5 & 0.596 & 0.384 & 0.765 \\
\hline (14) Irregulars/aggregates & 518 & 821 & 503 & 1452 & 247 & 97.6 & 619 & 0.488 & 0.337 & 0.618 \\
\hline (15) Spherical particles & 42 & 181 & 108 & 236 & 24.8 & 8.60 & 48.7 & 0.961 & 0.924 & 0.976 \\
\hline $\begin{array}{l}\text { All shape groups together } \\
\text { (regardless of shape) }\end{array}$ & 3165 & 899 & 489 & 1454 & 244 & 89.7 & 614 & 0.461 & 0.286 & 0.640 \\
\hline
\end{tabular}




\subsection{Relationships between Microphysical Properties}

\subsubsection{Cross-Sectional Area and Area Ratio}

The cross-sectional area versus particle size ( $A$ vs. $\left.D_{\max }\right)$ and area ratio versus particle size $\left(A_{\mathrm{r}}\right.$ vs. $\left.D_{\max }\right)$ relationships for the shape groups are analyzed in this section. The $A$ vs. $D_{\max }$ relationship is fitted to a power law given by Kuhn and Gultepe [26]:

$$
A=C_{1} \cdot\left(\frac{D_{\max }}{1 \mu \mathrm{m}}\right)^{C_{2}}
$$

Equation (3) yields straight lines on a logarithmic plot; therefore, the parameters $C_{1}$ and $C_{2}$ are determined from linear fits to the data expressed as $\log (A)$ versus $\log \left(D_{\max }\right)$, so that if all particles were spherical (i.e., they would appear circular in the images), $C_{1}$ and $C_{2}$ would be equal to $\frac{\pi}{4} \times 10^{-12} \mathrm{~m}^{2}$ and 2 , respectively.

The area ratio is calculated according to Equation (1) but can also be expressed as a power law function:

$$
A_{\mathrm{r}}=C_{3} \cdot\left(\frac{D_{\max }}{1 \mu \mathrm{m}}\right)^{C_{4}}
$$

where parameters $C_{3}$ and $C_{4}$ can be obtained from Equations (3) and (1) so that $C_{3}=C_{1} \times \frac{4}{\pi} \times 10^{12} \mathrm{~m}^{-2}$ and $C_{4}=C_{2}-2$.

Figure 5 shows the fitted $A$ vs. $D_{\max }(l e f t)$ and $A_{\mathrm{r}}$ vs. $D_{\max }$ (right) relationships as lines for each shape group. The point on each line represents the median of the distribution of $D_{\max }$, the lines' endpoints correspond to the percentiles $15.9 \%$ and $84.1 \%$, and hence, the spread of data is illustrated by the length of the line. The fit parameters $C_{1}$ and $C_{2}$ as well as the corresponding correlation coefficients, $R^{2}$, which are used to analyze correlation, are shown in Table 9. In general, judging from the correlation coefficient, $R_{a}^{2}$, in all shape groups, there is a good correlation $\left(R_{a}^{2} \geq 0.73\right)$ in the $A$ vs. $D_{\max }$ relationship. The shape groups (5) Plates, (11) Spatial stellar crystals, (12) Graupel, (13) Ice and melting or sublimating particles, (14) Irregulars and aggregates, and (15) Spherical particles have $R_{a}^{2}>0.9$.

For most shape groups, area ratio decreases with increasing particle size, as can be seen in Figure 5. Clearly, group (15) Spherical particles is an exception, and its area ratio is almost constant, i.e., size independent. A nearly constant $A_{\mathrm{r}}$ means that $C_{4} \simeq 0$ and $C_{2} \simeq 2$ (see Equations (3) and (4)), which is the case for this group. Two more groups have values of $C_{2}$ close to 2 . In group (12) Graupel, many particles have a close to spheroidal shape, and this appears to be similar over all sizes encountered, so that the area ratio is again size independent. The other group with $C_{2}$ fairly close to 2 and an almost constant $A_{\mathrm{r}}$ is (6) Stellar crystals. Apparently, the stellar particles in this group also remain similar at different sizes, so that $A_{\mathrm{r}}$ hardly varies. While $A_{\mathrm{r}}$ for group (15) Spherical particles is close to $1, A_{\mathrm{r}}$ for (6) Stellar crystals is much smaller, approximately 0.4 , as one would expect.

Particles in shape groups (1) Needles and thin or long columns, (2) Crossed needles and crossed columns, and (3) Thick columns and bullets, which are highly nonspherical, have $C_{2}$ values furthest from 2 . As a consequence, $C_{4}$ values are furthest from zero and these groups have the steepest size dependence of $A_{\mathrm{r}}$, as can be seen in Figure 5. 

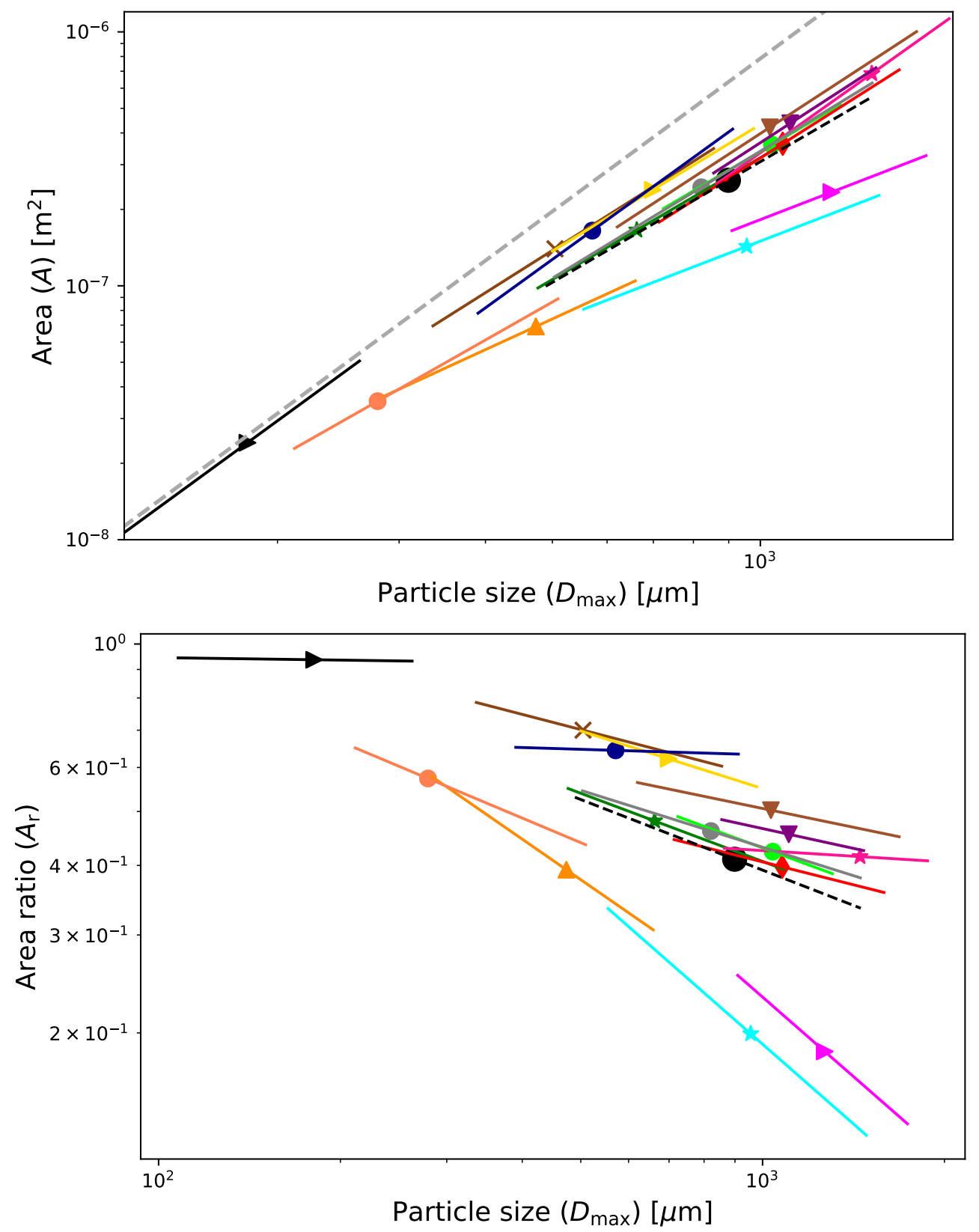

Figure 5. Area versus particle size ( $A$ vs. $\left.D_{\max }\right)$ and area ratio versus particle size $\left(A_{\mathrm{r}}\right.$ vs. $\left.D_{\max }\right)$ relationships for each shape group (solid lines) and for all data regardless of shape (black dashed lines) are shown. For a legend, see Figure 4 . Fits of $A$ versus $D_{\max }$ and $A_{\mathrm{r}}$ versus $D_{\max }$ relationships are shown in logarithmic scale. The median $D_{\max }$ of the data is represented as a single point on each line. The length of the fit lines are defined by percentiles $15.9 \%$ and $84.1 \%$ of $D_{\max }$. Top: $A$ vs. $D_{\max }$ relationship given by Equation (3). For comparison, the area of spheres given by $(\pi / 4) \cdot D_{\max }^{2}$ is shown as a gray dashed line. Bottom: $A_{\mathrm{r}}$ vs. $D_{\max }$ relationship given by Equation (4). The corresponding data are shown in Table 9.

Tables 8 and 9 as well as Figures 4 and 5 show, in addition to the results for each shape group described above, also the results of $A$ vs. $D_{\max }$ and $A_{\mathrm{r}}$ vs. $D_{\max }$ fits to all data (regardless of shape). These are provided as references and for situations where one might need average relationships instead of shape-dependent ones. 
Table 9. Area versus particle size ( $A$ vs. $\left.D_{\max }\right)$ and area ratio versus aspect ratio $\left(A_{\mathrm{r}} \mathrm{vs} . A_{\mathrm{s}}\right)$ relationships fitted to Equations (3) and (4) for each shape group and for all data, i.e., for all the shape groups regardless of shape. The parameters $C_{1}, C_{2}, C_{5}$, and $C_{6}$ and the correlation coefficients $R_{a}^{2}$ and $R_{b}^{2}$ are shown

\begin{tabular}{lcccccc}
\hline \multirow{2}{*}{ Shape Groups (1-15) } & \multicolumn{3}{c}{$\boldsymbol{A}$ vs. $\boldsymbol{D}_{\mathbf{m a x}}$} & \multicolumn{3}{c}{$\boldsymbol{A}_{\mathbf{r}}$ vs. $\boldsymbol{A}_{\mathbf{s}}$} \\
\cline { 2 - 7 } & $\boldsymbol{C}_{\mathbf{1}} \mathbf{1} \mathbf{1 0}^{-\mathbf{1 2}} \mathbf{~ m}^{\mathbf{2}}$ & $\boldsymbol{C}_{\mathbf{2}}$ & $\boldsymbol{R}_{\boldsymbol{a}}^{\mathbf{2}}$ & $\boldsymbol{C}_{\mathbf{5}}$ & $\boldsymbol{C}_{\mathbf{6}}$ & $\boldsymbol{R}_{\boldsymbol{b}}^{\mathbf{2}}$ \\
\hline (1) Needles and thin or long columns & 108 & 1.05 & 0.76 & 0.0183 & 0.698 & 0.90 \\
(2) Crossed needles and crossed columns & 128 & 1.05 & 0.73 & 0.0591 & 0.252 & 0.32 \\
(3) Thick columns and bullets & 31.6 & 1.25 & 0.85 & 0.0415 & 0.756 & 0.89 \\
(4) Capped columns and capped bullets & 5.31 & 1.59 & 0.79 & 0.0120 & 0.654 & 0.46 \\
(5) Plates & 3.17 & 1.72 & 0.94 & -0.00869 & 0.894 & 0.80 \\
(6) Stellar crystals & 0.531 & 1.93 & 0.86 & 0.123 & 0.395 & 0.25 \\
(7) Bullet rosettes & 5.35 & 1.60 & 0.82 & 0.0991 & 0.450 & 0.25 \\
(8) Branches & 2.11 & 1.73 & 0.84 & 0.0845 & 0.483 & 0.47 \\
(9) Side planes & 1.88 & 1.76 & 0.88 & 0.124 & 0.457 & 0.32 \\
(10) Spatial plates & 4.64 & 1.66 & 0.86 & 0.0718 & 0.698 & 0.61 \\
(11) Spatial stellar crystals & 1.88 & 1.78 & 0.95 & 0.0736 & 0.556 & 0.55 \\
(12) Graupel & 0.324 & 1.97 & 0.98 & 0.201 & 0.518 & 0.45 \\
(13) Ice and melting or sublimating particles & 5.87 & 1.54 & 0.91 & 0.0351 & 0.769 & 0.68 \\
(14) Irregulars and aggregates & 3.54 & 1.66 & 0.90 & 0.0158 & 0.648 & 0.52 \\
(15) Spherical particles & 0.795 & 1.99 & 0.99 & -0.168 & 1.14 & 0.93 \\
\hline \multicolumn{1}{c}{ All shape groups together } & & & & & & \\
$\quad$ (regardless of shape) & 5.66 & 1.58 & 0.83 & -0.451 & 0.900 & 0.71 \\
\hline
\end{tabular}

\subsubsection{Area Ratio and Aspect Ratio}

Area ratio versus aspect ratio $\left(A_{\mathrm{r}}\right.$ vs. $\left.A_{\mathrm{s}}\right)$ data can be fitted to the linear relationship:

$$
A_{\mathrm{r}}=C_{5}+C_{6} \cdot A_{\mathrm{s}}
$$

where $C_{5}$ and $C_{6}$ are the fit parameters.

Figure 6 shows the $A_{\mathrm{r}}$ vs. $A_{\mathrm{s}}$ relationship for each shape group. For comparison, the equality $A_{\mathrm{r}}=A_{\mathrm{s}}$ is displayed as a gray dashed line. We note that particles in shape groups (3) Thick columns and bullets, (5) Plates, (13) Ice and melting or sublimating particles, and (15) Spherical particles are closest to this line. As can be seen in Table 9, these groups, together with group (1) Needles and thin or long columns, have a good correlation between area and aspect ratio $\left(R_{b}^{2} \geq 0.7\right)$. On the other hand, shape groups (2) Crossed needles and crossed columns, (6) Stellar crystals, (7) Bullet rosettes, and (9) Side planes have a low correlation $\left(R_{b}^{2}<0.5\right)$. For instance, in the case of the shape group (6) Stellar crystals, this might be due to several factors: the empty space between their branches resulting in low $A_{\mathrm{r}}$ values and/or significant variations in $A_{\mathrm{s}}$ due to particle orientation. Shape groups (1) Needles and thin or long columns, (3) Thick columns and bullets, (5) Plates, and (15) Spherical particles have the highest correlation $\left(R_{b}^{2}>0.8\right)$. 


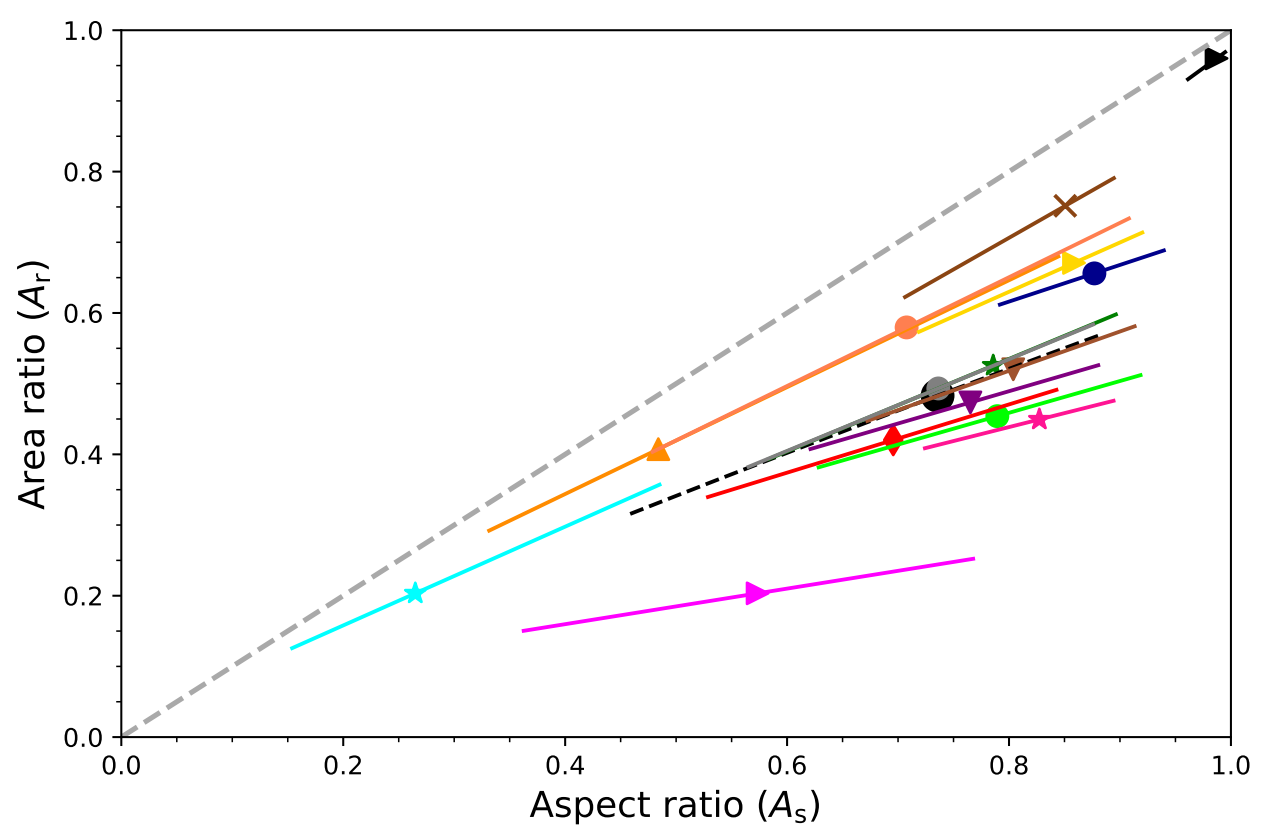

Figure 6. Area ratio versus aspect ratio ( $A_{\mathrm{r}}$ vs. $A_{\mathrm{s}}$ ) relationships for each shape group (solid lines) and for all data regardless of shape (black dashed lines) are shown. Fits for the $A_{\mathrm{r}} \mathrm{vs} . A_{\mathrm{s}}$ relationship are given by Equation (5). The median $A_{\mathrm{s}}$ is represented as a single point on each line. The lengths of the fit lines are defined by the percentiles $15.9 \%$ and $84.1 \%$ of $A_{\mathrm{s}}$. For comparison, spherical particles are shown $\left(A_{\mathrm{r}}=A_{\mathrm{S}}\right)$ as dashed gray line. For a legend, see Figure 4. Data are shown in Table 9.

\section{Summary and Conclusions}

This paper presents data and images of falling snow and other hydrometeors in the size range from $50 \mu \mathrm{m}$ to $4 \mathrm{~mm}$ by the D-ICI during snowfall events in Kiruna, Sweden from 2014 to 2019. The D-ICI takes dual high-resolution images (side and top view) that enable a better shape classification than if there was only one image per particle. From these images, we were able to determine the particle size, cross-sectional area, area ratio, and aspect ratio of individual particles.

We separated the particles into many different shapes following largely the Magono-Lee classification scheme. This resulted in an updated classification with 135 shapes, including 34 new shapes found in Kiruna during this period, which are shown in Figures A1 and A2. The new shapes are highlighted by gray frames. Table A1 (Appendix A) lists the full names of all the shapes, and the new shapes are denoted [KRN].

This study sought to find some characteristic microphysical properties, particle size, cross-sectional area, area ratio, aspect ratio, and frequency of occurrence of similar shapes. To facilitate this, we further sorted the 135 shapes into 15 shape groups based on morphological similarity. Naturally, it is also possible and, for some applications, more suitable to choose fewer groups.

Tables 4-7 (Section 4) show detailed descriptions of each of these groups, and a list with the complete names of the particle shapes sorted into the shape groups is given in Table A2 (Appendix B).

The main conclusions of this study can be summarized as follows:

- The dual images provides more information about the particle shape.

- We found 34 snow particles that are not yet described and that warrant their own shape in the updated shape classification.

- In our dataset, shape groups (1) Needles and thin or long columns, (8) Branches, (9) Side planes, and (14) Irregulars and aggregates are the most common, occurring more often than $10 \%$ of the time.

- Shape group (6) Stellar crystals has the largest median particle size, $D_{\max }=1450 \mu \mathrm{m}$, followed by shape groups (2) Crossed needles and crossed columns, (7) Bullet rosettes, (8) Branches, (9) Side planes, and (11) Spatial stellar crystals with $D_{\max }>1000 \mu \mathrm{m}$. Shape groups (3) Thick columns and bullets, 
(5) Plates, (13) Ice and melting or sublimating particles, and (15) Spherical particles have the smallest $D_{\max }<500 \mu \mathrm{m}$ (see Figure 4a).

- Shape group (6) Stellar crystals also has the largest median cross-sectional area, $A=6.34 \times 10^{-7} \mathrm{~m}^{2}$, followed by shape groups (7) Bullet rosettes, (8) Branches, (9) Side planes, and (11) Spatial stellar crystals with $A>3.0 \times 10^{-7} \mathrm{~m}^{2}$ (see Figure $4 \mathrm{~b}$ ).

- In general, groups with large particle sizes also have large areas. However, there are exceptional shape groups with the largest particle sizes but with smaller areas, as it is in the case of shape group (2) Crossed needles and crossed columns. We can see in Figure 4c, in which we note that shape groups (1) Needles and thin or long columns, (2) Crossed needles and crossed columns, and (3) Thick columns and bullets have the smallest area ratios, $A_{\mathrm{r}}<0.4$.

- In general, there is a good correlation of the $A$ vs. $D_{\max }$ relationship for the shape groups, with correlation coefficients varying from 0.73 for shape group (2) Crossed needles and crossed columns to over 0.9 for shape groups (5) Plates, (11) Spatial stellar crystals, (12) Graupel, (13) Ice and melting or sublimating particles, (14) Irregulars and aggregates, and (15) Spherical particles (see Table 9).

- In most shape groups, area ratio decreases with increasing particle size. This is strongest for the shape groups with the lowest area ratios: (1) Needles and thin or long columns, (2) Crossed needles and crossed columns, and (3) Thick columns and bullets, which consequently also have the lowest values of $C_{2}$. The shape groups (15) Spherical particles, (14) Graupel, and (6) Stellar crystals are exceptions and have area ratios that are almost constant.

- Shape groups (1) Needles and thin or long columns, (3) Thick columns and bullets, (5) Plates, and (15) Spherical particles have the highest correlation in the $A_{\mathrm{r}} \mathrm{vs} . A_{\mathrm{s}}$ relationship, with $R_{b}^{2}$ larger than 0.8 (see Table 9). On the other hand, shape groups (2) Crossed needles and crossed columns, (6) Stellar crystals, (7) Bullet rosettes, and (9) Side planes have correlation coefficients lower than 0.5. Shape groups (6) Stellar crystals and (7) Bullet rosettes have a particularly low $A_{r}$ vs. $A_{s}$ correlation of 0.25 despite a $A$ vs. $D_{\max }$ correlation larger than 0.82 . For instance, in the case of the shape group (6) Stellar crystals, this might be due to several factors; the empty space between their branches resulting in low $A_{\mathrm{r}}$ values and/or variations in $A_{\mathrm{s}}$ due to particle orientation.

This shows that, with the D-ICI and the classification in shapes and shape groups, particle characteristics can be studied for groups of similar shapes. Since fall speed can be measured by analyzing side-view images taken by the D-ICI [22], the shape dependence of fall speed can also be studied. The resulting parameterizations of the snow microphysical properties may be useful for improving our understanding of precipitation in cold climates in addition to helping improve the cloud microphysical parameterizations in the climate and forecast models.

Author Contributions: Methodology, S.V.-M. and T.K.; instrument, T.K.; formal analysis, S.V.-M. and T.K.; investigation, S.V.-M., T.K., and S.E.; data curation, S.V.-M. and T.K.; writing-original draft preparation, S.V.-M.; writing-review and editing, S.V.-M., T.K., and S.E.; visualization, S.V.-M.; supervision, T.K. and S.E. All authors have read and agreed to the published version of the manuscript.

Funding: This research received no external funding.

Acknowledgments: We like to thank the Graduate School of Space Technology at Luleå University of Technology for financial support and the Swedish Institute of Space Physics (IRF) at Kiruna for offering its facilities for our instrument.

Conflicts of Interest: The authors declare no conflict of interest.

\section{Appendix A. Shapes}

Table A1 shows the updated classification of natural snow crystals and other hydrometeors. Original particle shapes are from the Magono-Lee classification. Added shapes from Libbrecht [23] are marked as [Li] and from Kikuchi et al. [21] are marked as [Ki]. Gray background and [KRN] mark the new particle shapes found in Kiruna. 


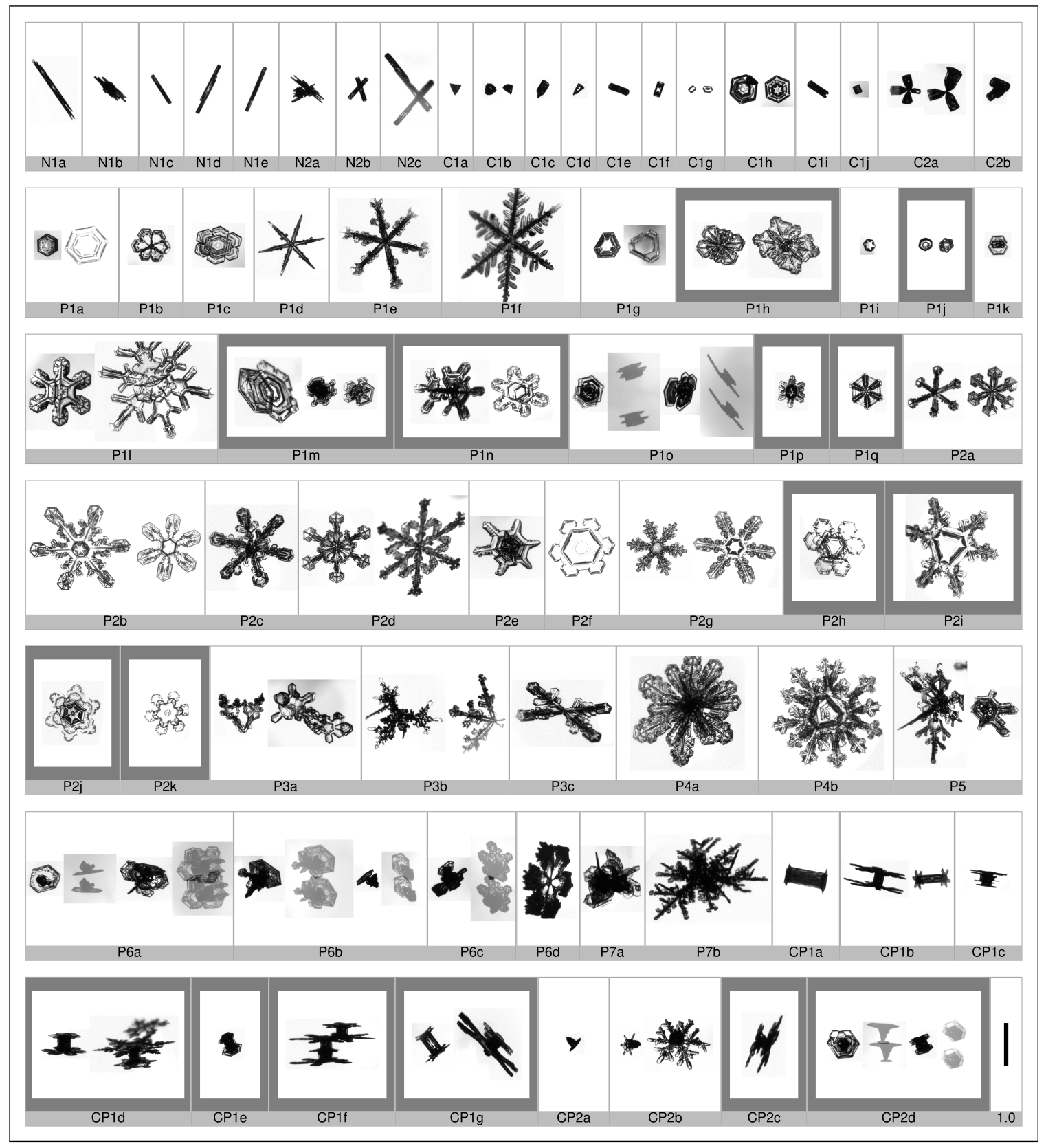

Figure A1. Updated shape classification (part 1): The 34 new shapes found in Kiruna are highlighted by thick gray frames. A list with the complete names of these shapes is shown in Table A1. Same scaling for all images: 1.0-mm scale bar is shown. 


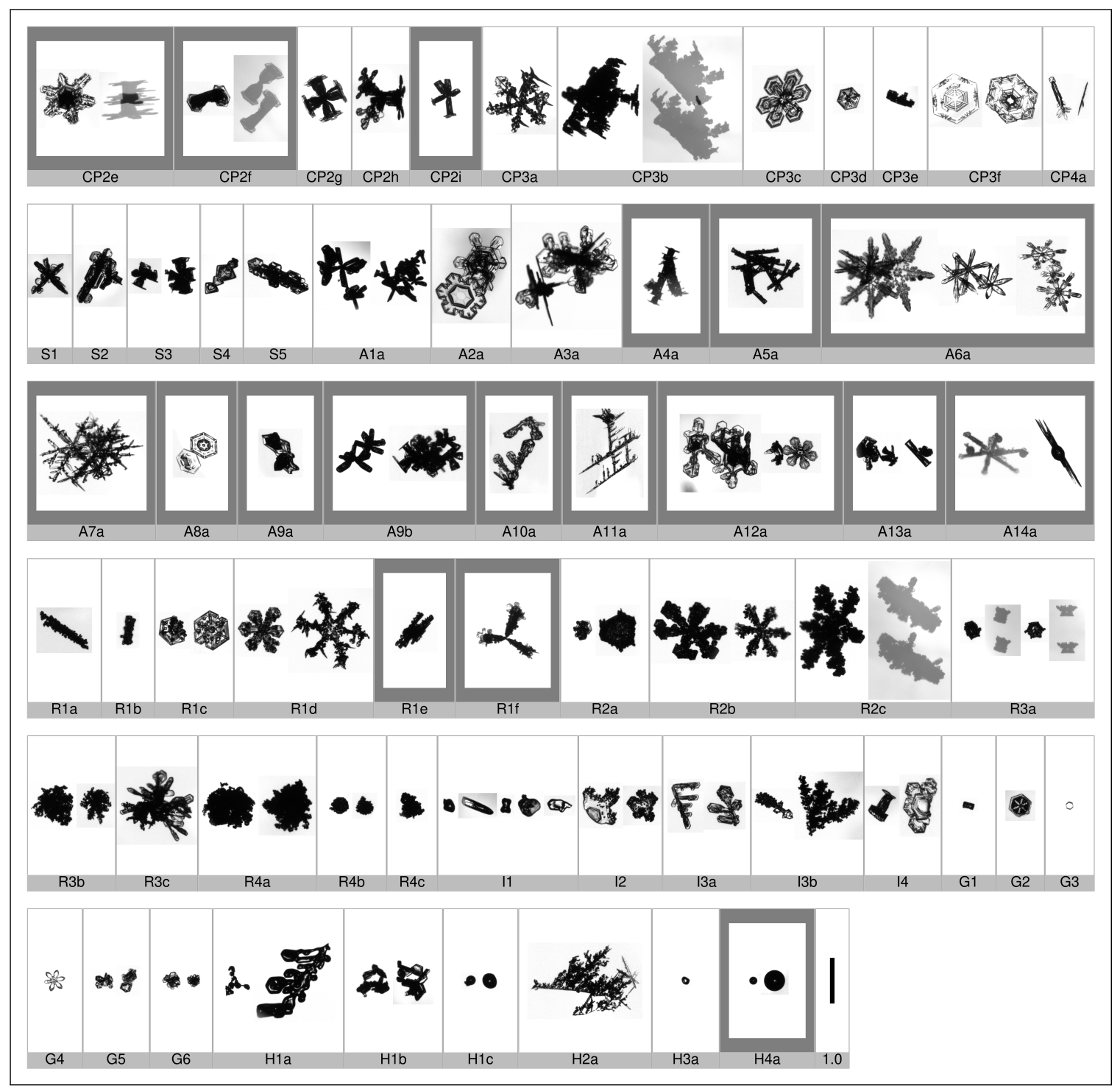

Figure A2. Updated shape classification with 135 different shapes (part 2): For caption, see Figure A1.

Table A1. Updated classification.

\begin{tabular}{ll}
\hline Level $(\mathbf{N}, \mathbf{C}, \ldots)$, Sublevel $(1,2, \ldots)$, Name & Label \\
\hline $\mathbf{N}=$ Needle crystal & \\
1. Simple needle & $\mathrm{N} 1 \mathrm{a}$ \\
$\quad$ a. Elementary needle & $\mathrm{N} 1 \mathrm{~b}$ \\
b. Bundle of elementary needles & $\mathrm{N} 1 \mathrm{c}$ \\
$\quad$ c. Elementary sheath & $\mathrm{N} 1 \mathrm{~d}$ \\
$\quad$ d. Bundle of elementary sheaths & $\mathrm{N} 1 \mathrm{e}$ \\
$\quad$ e. Long solid column & \\
2. Combination of needle crystals & $\mathrm{N} 2 \mathrm{a}$ \\
$\quad$ a. Combination of needles & $\mathrm{N} 2 \mathrm{~b}$ \\
$\quad$ b. Combination of sheaths & $\mathrm{N} 2 \mathrm{c}$ \\
$\quad$ c. Combination of long solid columns & \\
\hline C = Columnar crystal & \\
1. Simple column & \\
\hline
\end{tabular}


Table A1. Cont.

\begin{tabular}{lc}
\hline Level $(\mathbf{N}, \mathbf{C}, \ldots)$, Sublevel $(\mathbf{1}, \mathbf{2}, \ldots)$, Name & Label \\
\hline a. Pyramid & $\mathrm{C} 1 \mathrm{a}$ \\
b. Cup & $\mathrm{C} 1 \mathrm{~b}$ \\
c. Solid bullet & $\mathrm{C} 1 \mathrm{c}$ \\
d. Hollow bullet & $\mathrm{C} 1 \mathrm{~d}$ \\
e. Solid column & $\mathrm{C} 1 \mathrm{e}$ \\
f. Hollow column & $\mathrm{C} 1 \mathrm{f}$ \\
g. Solid thick plate & $\mathrm{C} 1 \mathrm{~g}$ \\
h. Thick plate of skeleton form & $\mathrm{C} 1 \mathrm{~h}$ \\
i. Scroll & $\mathrm{C} 1 \mathrm{i}$ \\
j. Twin columns & $\mathrm{C} 1 \mathrm{j}[\mathrm{Li}]$ \\
2. Combination of columns & \\
a. Combination of bullets (bullet rosettes) & $\mathrm{C} 2 \mathrm{a}$ \\
b. Combination of columns (column rosettes) & $\mathrm{C} 2 \mathrm{~b}$ \\
\hline
\end{tabular}

$\mathbf{P}=$ Plane crystal

1. Regular crystal developed in one plane
a. Hexagonal plate
P1a
b. Crystal with sector-like branches
$\mathrm{P} 1 \mathrm{~b}$
c. Crystal with broad branches
P1c
d. Stellar crystal
P1d
e. Ordinary dendritic crystal
P1e
f. Fernlike crystal
P1f
g. Triangular form/plate
P1g [Li]
h. Rectangular plate
P1h [KRN]
i. Hollow plate
P1i [Li]
j. Plate with a central hole
$\mathrm{P} 1 \mathrm{j}$ [KRN]
k. Split plate
P1k [Li]
1. Split stellar crystal
$\mathrm{P} 11$ [Li]
$\mathrm{m}$. Irregular split plate
$\mathrm{P} 1 \mathrm{~m}[K R N]$
n. Irregular split stellar crystal
$\mathrm{P} 1 \mathrm{n}[K R N]$
o. Double plate
P1o [Li]
p. Double stellar crystal
$\mathrm{P} 1 \mathrm{p}$ [KRN]
q. Stellar over plate P1q [KRN]

2. Plane crystal with extensions of different form
a. Stellar crystal with plates at ends
$\mathrm{P} 2 \mathrm{a}$
b. Stellar crystal with sector-like ends
$\mathrm{P} 2 \mathrm{~b}$
c. Dendritic crystal with plates at ends
$\mathrm{P} 2 \mathrm{c}$
d. Dendritic crystal with sector-like ends
$\mathrm{P} 2 \mathrm{~d}$
e. Plate with simple extensions
P2e
f. Plate with sector-like extensions
$\mathrm{P} 2 \mathrm{f}$
g. Plate with dendritic extensions
$\mathrm{P} 2 \mathrm{~g}$
h. Triangular form with plates at ends
$\mathrm{P} 2 \mathrm{~h}[K R N]$
i. Triangular form with dendrites at ends
$\mathrm{P} 2 \mathrm{i}[K R N]$
j. Concentric plates with sector-like extensions
P2j [KRN]
k. Concentric plates with stellar or dendritic extensions
$\mathrm{P} 2 \mathrm{k}[K R N]$

3. Crystals with irregular number of branches

a. Two-branched crystal 
Table A1. Cont.

\begin{tabular}{lc}
\hline Level $(\mathbf{N}, \mathbf{C}, \ldots)$, Sublevel $(\mathbf{1}, \mathbf{2}, \ldots)$, Name & Label \\
\hline b. Three-branched crystal & $\mathrm{P} 3 \mathrm{~b}$ \\
c. Four-branched crystal & $\mathrm{P3c}$ \\
4. Crystal with 12 branches & \\
a. Broad branch crystal with 12 branches \\
b. Dendritic crystal with 12 branches & $\mathrm{P} 4 \mathrm{a}$ \\
5. Malformed crystal & $\mathrm{P} 4 \mathrm{~b}$ \\
Many varieties & \\
6. Spatial assemblage of plane branches & $\mathrm{P} 5$ \\
a. Plate with spatial plates & \\
b. Plate with spatial dendrites & $\mathrm{P} 6 \mathrm{a}$ \\
c. Stellar crystal with spatial plates & $\mathrm{P} 6 \mathrm{~b}$ \\
d. Stellar crystal with spatial dendrites & $\mathrm{P} 6 \mathrm{c}$ \\
7. Radiating assemblage of plane branches & $\mathrm{P} 6 \mathrm{~d}$ \\
a. Radiating assemblage of plates & \\
b. Radiating assemblage of dendrites & $\mathrm{P} 7 \mathrm{a}$ \\
\hline
\end{tabular}

$\mathbf{C P}=$ Combination of column and plane crystals

1. Column with plane crystals at both ends
a. Column with plates (capped column)
CP1a
b. Column with dendrites
$\mathrm{CP} 1 \mathrm{~b}$
c. Multiple capped column
$\mathrm{CP} 1 \mathrm{c}$
d. Column with plate and dendrite
CP1d [KRN]
e. Asymmetric capped column (with plates)
CP1e [KRN]
f. Multiple capped column with dendrites
CP1f [KRN]
g. Asymmetric column with dendrites
CP1g [KRN]

2. Bullet with plane crystals
a. Bullet with plate
$\mathrm{CP} 2 \mathrm{a}[\mathrm{Ki}]$
b. Bullet with dendrite
$\mathrm{CP} 2 \mathrm{~b}$
c. Bullet with plate and dendrite
$\mathrm{CP} 2 \mathrm{c}[\mathrm{KRN}]$
d. Bullet with two plates
$\mathrm{CP} 2 \mathrm{~d}[K R N]$
e. Bullet with two dendrites
CP2e $[K R N]$
f. Combination of bullets (capped bullets)
$\mathrm{CP} 2 \mathrm{f}[\mathrm{KRN}]$
g. Combination of bullets with plates
$\mathrm{CP} 2 \mathrm{~g}[\mathrm{Ki}]$
h. Combination of bullets with dendrites
$\mathrm{CP} 2 \mathrm{~h}[\mathrm{Ki}]$
i. Asymmetric combination of bullets
CP2i [KRN]

3. Plane crystal with spatial extensions at ends

a. Stellar crystal (dendrite) with needles CP3a

b. Stellar crystal (dendrite) with columns CP3b

c. Stellar crystal (dendrite) with scrolls at ends $\quad$ CP3c

d. Plate with needles $\quad$ CP3d [Ki]

e. Plate with columns CP3e [Ki]

f. Plate with scrolls at ends $\quad$ CP3f

4. Seagull-type crystal
a. Seagull crystal
$\mathrm{CP} 4 \mathrm{a}[\mathrm{Ki}]$

$\mathrm{S}=$ Columnar crystals with extended side planes

1. Side planes

2. Scale-like side planes 
Table A1. Cont.

\begin{tabular}{lc}
\hline Level $(\mathbf{N}, \mathbf{C}, \ldots)$, Sublevel $(\mathbf{1}, \mathbf{2}, \ldots)$, Name & Label \\
\hline 3. Combination of side planes, bullets, and columns & $\mathrm{S} 3$ \\
4. Arrowhead twins & $\mathrm{S} 4[\mathrm{Li}]$ \\
5. Crossed plates & $\mathrm{S} 5[\mathrm{Li}]$ \\
\hline
\end{tabular}

A = Aggregates of snow crystals

1. Aggregation of column-type crystals

a. Aggregation of combinations of columns and bullets A1a [Ki]

2. Aggregation of plane-type crystals

a. Aggregation of combinations of plates and dendrites $\quad$ A2a $[\mathrm{Ki}]$

3. Aggregation of column- and plane-type crystals

a. Aggregation of combinations of columns,

A3a $[K i]$

planes and crossed plates

4. Aggregation of multiple capped columns

a. Aggregation of multiple capped columns

$\mathrm{A} 4 \mathrm{a}[K R N]$

5. Aggregation of needle- and sheath-type crystals

a. Aggregation of needles and sheaths

$\mathrm{A} 5 \mathrm{a}[K R N]$

6. Aggregation of stellar-type crystals

a. Aggregation of stellar crystals

A6a [KRN]

7. Aggregation of dendrite-type crystals

a. Aggregation of dendrite crystals

$\mathrm{A} 7 \mathrm{a}[K R N]$

8. Aggregation of plate-type crystals

a. Aggregation of plates

$\mathrm{A} 8 \mathrm{a}[K R N]$

9. Aggregation of bullet-type crystals
a. Aggregation of bullets
A9a [KRN]
b. Aggregation of bullet rosettes and capped bullets
$\mathrm{A} 9 \mathrm{~b}[K R N]$

10. Aggregation of branch-type crystals
a. Aggregation of branches
A10a [KRN]

11. Aggregation of seagull-type crystals

a. Aggregation of seagull

A11a [KRN]

12. Aggregation of malformed-type crystals

a. Aggregation of malformed crystals

A12a [KRN]

13. Aggregation of irregular-type crystals

a. Aggregation of irregular particles

A13a [KRN]

14. Aggregation of frozen small raindrops and snow crystals
a. Aggregation of frozen small raindrops
A14a [KRN] and snow crystals

R = Rimed crystal (crystal with cloud droplets attached)

1. Rimed crystal
a. Rimed needle crystal
R1a
b. Rimed columnar crystal
$\mathrm{R} 1 \mathrm{~b}$
c. Rimed plate or sector
R1c
d. Rimed stellar crystal
R1d
e. Rimed bundle
f. Rimed capped bullet
R1f [KRN]

2. Densely rimed crystal

a. Densely rimed plate or sector

$\mathrm{R} 2 \mathrm{a}$ 
Table A1. Cont.

\begin{tabular}{lc}
\hline Level $(\mathbf{N}, \mathbf{C}, \ldots)$, Sublevel $(\mathbf{1}, \mathbf{2}, \ldots)$, Name & Label \\
\hline \multicolumn{1}{c}{ b. Densely rimed stellar crystal } & $\mathrm{R} 2 \mathrm{~b}$ \\
c. Stellar crystal with rimed spatial branches & $\mathrm{R} 2 \mathrm{c}$ \\
3. Graupel-like snow & \\
a. Graupel-like snow of hexagonal type & $\mathrm{R} 3 \mathrm{a}$ \\
b. Graupel-like snow of lump type & $\mathrm{R} 3 \mathrm{~b}$ \\
$\quad$ c. Graupel-like snow with non-rimed extensions & $\mathrm{R} 3 \mathrm{c}$ \\
4. Graupel & $\mathrm{R} 4 \mathrm{a}$ \\
$\quad$ a. Hexagonal graupel & $\mathrm{R} 4 \mathrm{~b}$ \\
b. Lump graupel & $\mathrm{R} 4 \mathrm{c}$ \\
$\quad$ c. Cone-like graupel & \\
\hline I = Irregular snow crystal & $\mathrm{I} 1$ \\
1. Ice particle & $\mathrm{I} 2$ \\
2. Rimed particle & \\
3. Broken piece from a crystal & $\mathrm{I} 3 \mathrm{a}$ \\
a. Broken branch & $\mathrm{I} 3 \mathrm{~b}$ \\
b. Rimed broken branch & $\mathrm{I} 4$ \\
\hline
\end{tabular}

$\mathrm{G}=$ Germ of snow crystal (ice crystal)

1. Minute column $\quad$ G1

2. Germ of skeleton form $\quad$ G2

3. Minute hexagonal plate G3

4. Minute stellar crystal G4

5. Minute assemblage of plates G5

6. Irregular germ G6

\section{$\mathbf{H}=$ Other solid precipitation particles}

1. Frozen hydrometeor particle
a. Frozen cloud particle
$\mathrm{H} 1 \mathrm{a}[\mathrm{Ki}]$
b. Chained frozen cloud particles
$\mathrm{H} 1 \mathrm{~b}$ [Ki]
c. Frozen small raindrop
$\mathrm{H} 1 \mathrm{c}[\mathrm{Ki}]$

2. Sleet particle
a. Sleet particle
$\mathrm{H} 2 \mathrm{a}[\mathrm{Ki}]$

3. Ice pellet

a. Ice pellet

$\mathrm{H} 3 \mathrm{a}[\mathrm{Ki}]$

4. Droplets of water

a. Raindrop H4a [KRN]

\section{Appendix B. Shape Groups}

Table A2 shows the shapes of the updated classification of natural snow crystals and other hydrometeors sorted into shape groups. Original particle shapes are from the Magono-Lee classification. Shapes from Libbrecht [23] are marked as [Li], and shapes from Kikuchi et al. [21] are marked as [Ki]. Gray background and [KRN] mark the new particle shapes found in Kiruna. 
Table A2. Shapes of the updated classification sorted into shape groups.

\begin{tabular}{|c|c|}
\hline Shape Groups (1-15), Name & Label \\
\hline \multicolumn{2}{|l|}{ (1) Needles and thin or long column } \\
\hline Elementary needle & N1a \\
\hline Bundle of elementary needles & $\mathrm{N} 1 \mathrm{~b}$ \\
\hline Elementary sheath & N1c \\
\hline Bundle of elementary sheaths & N1d \\
\hline Long solid column & N1e \\
\hline Rimed needle crystal & R1a \\
\hline Rimed columnar crystal & $\mathrm{R} 1 \mathrm{~b}$ \\
\hline Rimed bundle & R1e [KRN] \\
\hline \multicolumn{2}{|l|}{ (2) Crossed needles and crossed columns } \\
\hline Combination of needles & $\mathrm{N} 2 \mathrm{a}$ \\
\hline Combination of sheaths & $\mathrm{N} 2 \mathrm{~b}$ \\
\hline Combination of long solid columns & $\mathrm{N} 2 \mathrm{c}$ \\
\hline \multicolumn{2}{|l|}{ (3) Thick columns and bullets } \\
\hline Pyramid & $\mathrm{C} 1 \mathrm{a}$ \\
\hline Cup & $\mathrm{C} 1 \mathrm{~b}$ \\
\hline Solid bullet & $\mathrm{C} 1 \mathrm{c}$ \\
\hline Hollow bullet & $\mathrm{C} 1 \mathrm{~d}$ \\
\hline Solid column & $\mathrm{C} 1 \mathrm{e}$ \\
\hline Hollow column & C1f \\
\hline Solid thick plate & $\mathrm{C} 1 \mathrm{~g}$ \\
\hline Scroll & $\mathrm{C} 1 \mathrm{i}$ \\
\hline Twin columns & $\mathrm{C} 1 \mathrm{j}[L i]$ \\
\hline Minute column & G1 \\
\hline \multicolumn{2}{|l|}{ (4) Capped columns and capped bullets } \\
\hline Column with plates (capped column) & CP1a \\
\hline Column with dendrites & $\mathrm{CP} 1 \mathrm{~b}$ \\
\hline Multiple capped column & $\mathrm{CP} 1 \mathrm{c}$ \\
\hline Column with plate and dendrite & CP1d [KRN] \\
\hline Asymmetric capped column (with plates) & $\mathrm{P} 1 \mathrm{e}[K R N]$ \\
\hline Multiple capped column with dendrites & CP1f [KRN] \\
\hline Asymmetric column with dendrites & $\mathrm{CP} 1 \mathrm{~g}$ [KRN] \\
\hline Bullet with plate & CP2a $[K i]$ \\
\hline Bullet with dendrite & $\mathrm{CP} 2 \mathrm{~b}$ \\
\hline Bullet with plate and dendrite & $\mathrm{CP} 2 \mathrm{c}[\mathrm{KRN}]$ \\
\hline Bullet with two plates & $\mathrm{CP} 2 \mathrm{~d}[K R N]$ \\
\hline Bullet with two dendrites & $\mathrm{CP} 2 \mathrm{e}[\mathrm{KRN}]$ \\
\hline Combination of bullets (capped bullets) & $\mathrm{CP} 2 \mathrm{f}[K R N]$ \\
\hline \multicolumn{2}{|l|}{ (5) Plates } \\
\hline Thick plate of skeleton form & $\mathrm{C} 1 \mathrm{~h}$ \\
\hline Hexagonal plate & P1a \\
\hline Crystal with sector-like branches & $\mathrm{P} 1 \mathrm{~b}$ \\
\hline Crystal with broad branches & P1c \\
\hline Triangular form/plate & $\mathrm{P} 1 \mathrm{~g}[\mathrm{Li}]$ \\
\hline
\end{tabular}


Table A2. Cont.

\begin{tabular}{lc}
\hline Shape Groups (1-15), Name & Label \\
\hline Rectangular plate & $\mathrm{P} 1 \mathrm{~h}[\mathrm{KRN}]$ \\
Hollow plate & $\mathrm{P} 1 \mathrm{i}[\mathrm{Li}]$ \\
Plate with a central hole & $\mathrm{P} 1 \mathrm{j}[\mathrm{KRN}]$ \\
Split plate & $\mathrm{P} 1 \mathrm{k}[\mathrm{Li}]$ \\
Irregular split plate & $\mathrm{P} 1 \mathrm{~m}[\mathrm{KRN}]$ \\
Double plate & $\mathrm{P} 1 \mathrm{o}[\mathrm{Li}]$ \\
Stellar crystal over plate & $\mathrm{P} 1 \mathrm{q}[\mathrm{KRN}]$ \\
Plate with scrolls at ends & $\mathrm{CP} 3 \mathrm{f}$ \\
Rimed plate or sector & $\mathrm{R} 1 \mathrm{c}$ \\
Germ of skeleton from & $\mathrm{G} 2$ \\
Minute hexagonal plate & $\mathrm{G} 3$ \\
\hline
\end{tabular}

\section{(6) Stellar crystals}

Stellar crystal $\quad$ P1d

Ordinary dendritic crystal P1e

Fernlike crystal P1f

Split stellar crystal $\quad$ P11 [Li]

Irregular split stellar crystal $\quad$ P1n [KRN]

Double stellar crystal $\quad$ P1p [KRN]

$\begin{array}{ll}\text { Stellar crystal with plates at ends } & \text { P2a }\end{array}$

$\begin{array}{ll}\text { Stellar crystal with sector-like ends } & \mathrm{P} 2 \mathrm{~b}\end{array}$

$\begin{array}{ll}\text { Dendritic crystal with plates at ends } & \text { P2c }\end{array}$

Dendritic crystal with sector-like ends $\quad$ P2d

$\begin{array}{ll}\text { Plate with simple extensions } & \text { P2e }\end{array}$

Plate with sector-like extensions $\quad$ P2f

Plate with dendritic extensions $\quad$ P2g

Triangular form with plates at ends $\quad$ P2h [KRN]

$\begin{array}{ll}\text { Triangular form with dendrites at ends } & \text { P2i [KRN] }\end{array}$

Concentric plates with sector-like extensions $\quad P 2 \mathrm{j}[K R N]$

Concentric plates with stellar or dendritic extensions $\quad$ P2k [KRN]

Broad branch crystal with 12 branches P4a

Dendritic crystal with 12 branches $\quad P 4 b$

Stellar crystal with scrolls at ends $\quad$ CP3c

Rimed stellar crystal R1d

$\begin{array}{ll}\text { Minute stellar crystal } & \text { G4 }\end{array}$

(7) Bullet rosettes

Combination of bullets (bullet rosettes) C2a

Combination of columns (column rosettes) $\quad \mathrm{C} 2 \mathrm{~b}$

Combination of bullets with plates $\quad \mathrm{CP} 2 \mathrm{~g}[\mathrm{Ki}]$

Combination of bullets with dendrites $\quad \mathrm{CP} 2 \mathrm{~h}[\mathrm{Ki}]$

Asymmetric combination of bullets $\quad$ CP2i [KRN]

$\begin{array}{ll}\text { Rimed capped bullet } & \text { R1f [KRN] }\end{array}$

(8) Branches

$\begin{array}{ll}\text { Two-branched crystal } & \text { P3a }\end{array}$

Three-branched crystal P3b

Four-branched crystal $\quad$ P3c

$\begin{array}{ll}\text { Malformed crystal } & \text { P5 }\end{array}$ 
Table A2. Cont.

\begin{tabular}{|c|c|}
\hline Shape Groups (1-15), Name & Label \\
\hline Radiating assemblage of dendrites & $\mathrm{P} 7 \mathrm{~b}$ \\
\hline Seagull crystal & $\mathrm{CP} 4 \mathrm{a}[\mathrm{Ki}]$ \\
\hline Broken branch & $\mathrm{I} 3 \mathrm{a}$ \\
\hline Rimed broken branch & $\mathrm{I} 3 \mathrm{~b}$ \\
\hline \multicolumn{2}{|l|}{ (9) Side planes } \\
\hline Radiating assemblage plates & $\mathrm{P7a}$ \\
\hline Side planes & S1 \\
\hline Scale-like side planes & S2 \\
\hline Combination of side planes, bullets, and columns & S3 \\
\hline Arrowhead twins & $\mathrm{S} 4[\mathrm{Li}]$ \\
\hline Crossed plates & S5 [Li] \\
\hline Minute assemblage of plates & G5 \\
\hline \multicolumn{2}{|l|}{ (10) Spatial plates } \\
\hline Plate with spatial plates & P6a \\
\hline Plate with spatial dendrites & P6b \\
\hline Plate with needles & $\mathrm{CP} 3 \mathrm{~d}[\mathrm{Ki}]$ \\
\hline Plate with columns & CP3e $[K i]$ \\
\hline Densely rimed plate or sector & $\mathrm{R} 2 \mathrm{a}$ \\
\hline \multicolumn{2}{|l|}{ (11) Spatial stellar crystals } \\
\hline Stellar crystal with spatial plates & P6c \\
\hline Stellar crystal with spatial dendrites & P6d \\
\hline Stellar crystal with needles & CP3a \\
\hline Stellar crystal with columns & $\mathrm{CP} 3 \mathrm{~b}$ \\
\hline Densely rimed stellar crystal & $\mathrm{R} 2 \mathrm{~b}$ \\
\hline Stellar crystal with rimed spatial branches & $\mathrm{R} 2 \mathrm{c}$ \\
\hline Graupel-like snow of hexagonal type & $\mathrm{R} 3 \mathrm{a}$ \\
\hline Graupel-like snow of lump type & $\mathrm{R} 3 \mathrm{~b}$ \\
\hline Graupel-like snow with non-rimed extensions & $\mathrm{R} 3 \mathrm{c}$ \\
\hline \multicolumn{2}{|l|}{ (12) Graupel } \\
\hline Hexagonal graupel & $\mathrm{R} 4 \mathrm{a}$ \\
\hline Lump graupel & $\mathrm{R} 4 \mathrm{~b}$ \\
\hline Cone-like graupel & $\mathrm{R} 4 \mathrm{c}$ \\
\hline \multicolumn{2}{|l|}{ (13) Ice and melting or sublimating particles } \\
\hline Ice particle & $\mathrm{I} 1$ \\
\hline Frozen cloud particle & $\mathrm{H} 1 \mathrm{a}[\mathrm{Ki}]$ \\
\hline Chained frozen cloud particles & $\mathrm{H} 1 \mathrm{~b}[\mathrm{Ki}]$ \\
\hline Sleet particle & $\mathrm{H} 2 \mathrm{a}[\mathrm{Ki}]$ \\
\hline Ice pellet & $\mathrm{H} 3 \mathrm{a}[\mathrm{Ki}]$ \\
\hline \multicolumn{2}{|l|}{ (14) Irregulars and aggregates } \\
\hline Aggregation of combinations of columns and bullets & A1a $[K i]$ \\
\hline Aggregation of combinations of plates and dendrites & $\mathrm{A} 2 \mathrm{a}[\mathrm{Ki}]$ \\
\hline $\begin{array}{l}\text { Aggregation of combinations of columns, planes } \\
\text { and crossed plates }\end{array}$ & $\mathrm{A} 3 \mathrm{a}[\mathrm{Ki}]$ \\
\hline Aggregation of multiple capped columns & $\mathrm{A} 4 \mathrm{a}[K R N]$ \\
\hline
\end{tabular}


Table A2. Cont.

\begin{tabular}{lc}
\hline Shape Groups (1-15), Name & Label \\
\hline Aggregation of needles and sheaths & A5a [KRN] \\
Aggregation of stellar crystals & A6a [KRN] \\
Aggregation of dendrite crystals & A7a [KRN] \\
Aggregation of plates & A8a [KRN] \\
Aggregation of bullets & A9a [KRN] \\
Aggregation of bullet rosettes and capped bullets & A9b [KRN] \\
Aggregation of branches & A10a [KRN] \\
Aggregation of seagull & $\mathrm{A} 11 \mathrm{a}[K R N]$ \\
Aggregation of malformed crystals & $\mathrm{A} 12 \mathrm{a}[K R N]$ \\
Aggregation of irregular particles & $\mathrm{A} 13 \mathrm{a}[K R N]$ \\
Aggregation of frozen small raindrops and snow crystals & $\mathrm{A} 14 \mathrm{a}$ [KRN] \\
Rimed particle & $\mathrm{I} 2$ \\
Miscellaneous & $\mathrm{I} 4$ \\
Irregular germ & $\mathrm{G6}$ \\
\hline (15) Spherical particles & \\
Frozen small raindrop & $\mathrm{H} 1 \mathrm{c}[K i]$ \\
Raindrop & $\mathrm{H} 4 \mathrm{a}[K R N]$ \\
\hline
\end{tabular}

\section{References}

1. Stoelinga, M.; Hobbs, P.V.; Mass, C.F.; Locatelli, J.; Colle, B.; Houze, R.; Rangno, A.L.; Bond, N.A.; Smull, B.F.; Rasmussen, R.M.; et al. Improvement of Microphysical Parameterization through Observational Verification Experiment (IMPROVE). Bull. Am. Met. Soc. 2003, 84, 1807-1826. [CrossRef]

2. Tao, W.K.; Simpson, J.; Baker, D.; Braun, S.; Chou, M.D.; Ferrier, B.; Johnson, D.; Khain, A.; Lang, S.; Lynn, B.; et al. Microphysics, radiation and surface processes in the Goddard Cumulus Ensemble (GCE) model. Meteorol. Atmos. Phys. 2003, 82, 97-137. [CrossRef]

3. Posselt, D.J.; L'Ecuyer, T.S.; Stephens, G.L. Exploring the error characteristics of thin ice cloud property retrievals using a Markov chain Monte Carlo algorithm. J. Geophys. Res. 2008, 113. [CrossRef]

4. Zhang, Z.; Yang, P.; Kattawar, G.; Riedi, J.; Labonnote, L.C.; Baum, B.A.; Platnick, S.; Huang, H.L. Influence of ice particle model on satellite ice cloud retrieval: lessons learned from MODIS and POLDER cloud product comparison. Atmos. Chem. Phys. 2009, 9, 7115-7129. [CrossRef]

5. Cooper, S.J.; Garrett, T.J. Identification of small ice cloud particles using passive radiometric observations. J. Appl. Meteorol. 2010, 49, 2334-2347. [CrossRef]

6. IPCC. Clouds and Aerosols. In Climate Change 2013-The Physical Science Basis: Working Group I Contribution to the Fifth Assessment Report of the Intergovernmental Panel on Climate Change; Cambridge University Press: Cambridge, UK, 2014; pp. 571-658. [CrossRef]

7. Pruppacher, H.R.; Klett, J.D. Microphysics of Clouds and Precipitation, 2nd ed.; Dordrecht: Kluwer Academic Publishers: Dordrecht, The Netherlands, 1997.

8. Nakaya, U.; Sekido, Y. General Classification of Snow Crystals and their Frequency of Occurrence. J. Fac. Sci. Hokkaido Imp. Univ. Ser. II 1936, 1, 243-264.

9. Hanajima, M. On the conditions for the formation of snow crystals. J. Meteorol. Soc. Jpn. Ser. II 1942, 20, 238-251._238. [CrossRef]

10. Nakaya, U. Snow Crystal Growth: Electron Microscope Study of Snow Crystal Nuclei (Advance communication). J. Glaciol. 1951, 1, 550. [CrossRef]

11. Nakaya, U. The Formation of Ice Crystals; American Meteorological Society: Boston, MA, USA, 1951; pp. 207-220._18. [CrossRef]

12. Itoo, K. On the Growth of Ice Crystals in the Air. Pap. Meteor. Geophys. 1951, 2, 315-316. [CrossRef] 
13. Isono, K. An Electron-Microscope Study of Ice Crystal Formation - A Preliminary Report. J. Meteorol. Soc. Jpn. Ser. II 1953, 31, 318-322. [CrossRef]

14. Isono, K. On the Growth of Ice-Crystals in the Air. J. Meteorol. Soc. Jpn. Ser. II 1957, 35A, 31-37. [CrossRef]

15. Ukitiro, N.; Masando, H.; Jiro, M. Physical Investigations on the Growth of Snow Crystals. J. Fac. Sci. Hokkaido Univ. Ser. II 1958, 5, 88-118.

16. Libbrecht, K.G. Morphogenesis on Ice: The Physics of Snow Crystals. Eng. Sci. 2001, I, 10-19.

17. Libbrecht, K.G. The physics of snow crystals. Rep. Prog. Phys. 2005, 68, 855-895. [CrossRef]

18. Seasonal Snow Cover: a guide for measurement compilation and assemblage of data. Unesco/IASH/WMO, 1970. Available online: https://globalcryospherewatch.org/bestpractices/docs/UNESCO_snow_cover_ 1970.pdf (accessed on 4 December 2019).

19. Fierz, C.; Armstrong, R.; Durand, Y.; Etchevers, P.; Greene, E.; McClung, D.; Nishimura, K.; Satyawali, P.; Sokratov, S. The International Classification for Seasonal Snow on the Ground (UNESCO, IHP (International Hydrological Programme)_VII, Technical Documents in Hydrology, No 83); IACS (International Association of Cryospheric Sciences) Contribution No 1; UNESCO/Division of Water Sciences: Paris, France, 2009.

20. Magono, C.; Lee, C.W. Meteorological classification of natural snow crystals. J. Fac. Sci. Hokkaido Univ. 1966, II, 321-335.

21. Kikuchi, K.; Kameda, T.; Higuchi, K.; Yamashita, A. A global classification of snow crystals, ice crystals, and solid precipitation based on observations from middle latitudes to polar regions. Atmos. Res. 2013, 132-133, 460-472. [CrossRef]

22. Kuhn, T.; Vázquez-Martín, S. Microphysical properties and fall speed measurements of snow ice crystals using the Dual Ice Crystal Imager (D-ICI). Atmos. Meas. Tech. Discuss. 2019, 1-24. [CrossRef]

23. Libbrecht, K.G. Ken Libbrecht's Field Guide to Snowflakes; Voyageur Press: Minneapolis, MN, USA, 2006.

24. SMHI. Januari 2018_Lufttemperatur och vind, SMHI_vov_temperature_wind_jan18. Available online: https: / / www.ce.se/smhi-sveriges-meteorologiska-och-hydrologiska-institut/ (accessed on 4 December 2019).

25. IRF. Weather at IRF. Available online: http:/ /www2.irf.se/weather/ (accessed on 4 December 2019).

26. Kuhn, T.; Gultepe, I. Ice Fog and Light Snow Measurements Using a High-Resolution Camera System. Pure Appl. Geophys. 2016, 173, 3049-3064. [CrossRef]

(C) 2020 by the authors. Licensee MDPI, Basel, Switzerland. This article is an open access article distributed under the terms and conditions of the Creative Commons Attribution (CC BY) license (http://creativecommons.org/licenses/by/4.0/). 